\title{
DIFFERENTIAL SOIL IMPEDANCE OBSTACLE DETECTION
}

\author{
FINAL REPORT
}

March 25, 2002-September 30,2004

Principal Investigator: Maximillian J. Kieba

Project Manager: Christopher J. Ziolkowski

847-768-0549, chris.ziolkowski@gastechnology.org

Report Issue Date: January 17, 2005

DOE Contract \#: DE-FC26-02NT41318

\author{
Submitted by
}

Gas Technology Institute

1700 South Mount Prospect Road

Des Plaines, Illinois 60018

GTI Project Number: 15328 (formerly 61152)

\author{
Submitted to \\ NETL AAD Document Control Bldg. 921 \\ U.S. Department of Energy \\ National Energy Technology Laboratory \\ P.O. Box 10940 \\ Pittsburgh, PA 15236-0940
}

DOE Project Officer

Richard Baker 


\section{DISCLAIMER}

“This report was prepared as an account of work sponsored by an agency of the United States Government and the Gas Technology Institute (GTI). Neither the United States Government, nor GTI, nor any agency thereof, nor any of their employees, makes any warranty, express or implied, or assumes any legal liability or responsibility for the accuracy, completeness, or usefulness of any information, apparatus, product, or process disclosed, or represents that its use would not infringe privately owned rights. Reference herein to any specific commercial product, process, or service by trade name, trademark, manufacturer, or otherwise does not necessarily constitute or imply its endorsement, recommendation, or favoring by the United States Government, GTI, or any agency thereof. The views and opinions of authors expressed herein do not necessarily state or reflect those of the United States Government or any agency thereof.” 


\begin{abstract}
This project aimed at developing a new and unique obstacle detection sensor for horizontal directional drilling (HDD) equipment. The development of this new technology will greatly improve the reliability and safety of natural gas HDD construction practices. This sensor utilizes a differential soil impedance measurement technique that will be sensitive to the presence of plastic and ceramic, as well as metallic obstacles.

The use of HDD equipment has risen significantly in the gas industry because HDD provides a much more cost-effective and less disruptive method for gas pipe installation than older, trenching methods. However, there have been isolated strikes of underground utilities by HDD equipment, which may have been avoided if methods were available to detect other underground obstacles when using HDD systems. GTI advisors from the gas industry ranked the value of solving the obstacle detection problem as the most important research and development project for GTI to pursue using Federal Energy Regulatory Commission (FERC) funds available through its industry partner, GRI.
\end{abstract}

GTI proposed to develop a prototype down-hole sensor system that is simple and compact. The sensor utilizes an impedance measurement technique that is sensitive to the presence of metallic or nonmetallic objects in the proximity of the HDD head. The system will use a simple sensor incorporated into the drill head. The impedance of the soil will be measured with a low frequency signal injected through the drill head itself. A pair of bridge type impedance sensors, mounted orthogonal to one another, is coupled to the soil. Inclusions in the soil will cause changes to the sensor balance distinguishable from homogeneous soil.

The sensor will provide range and direction data for obstacles near the HDD head. The goal is to provide a simple, robust system that provides the information required to avoid obstacles. This must be done within the size and ruggedness constraints of the HDD equipment. Imaging obstacles is not within the scope of this work, as it would require a more elaborate sensor than is practical within the HDD head. 


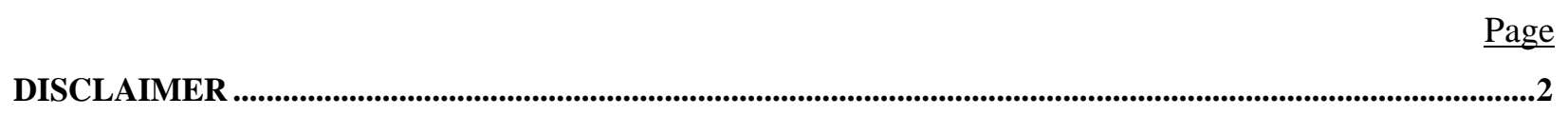

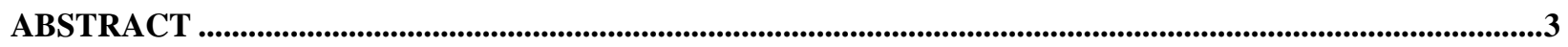

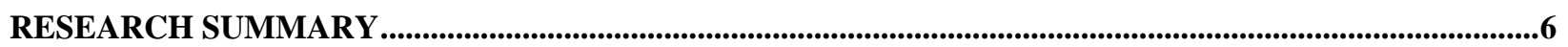

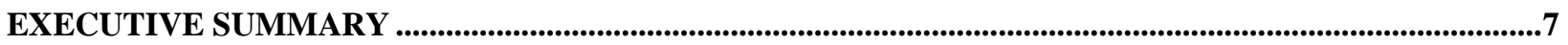

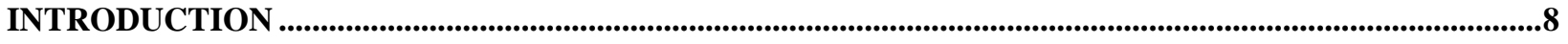

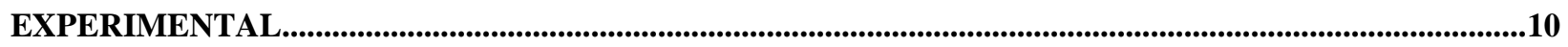

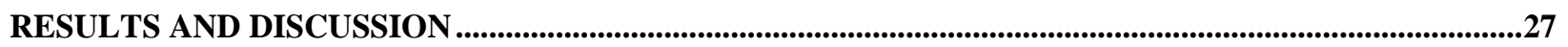

CONCLUSIONS

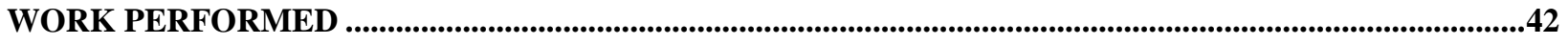

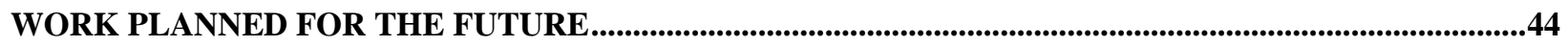

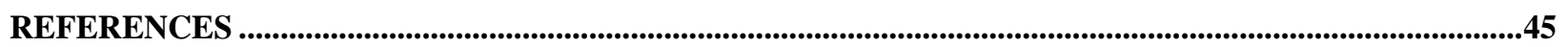

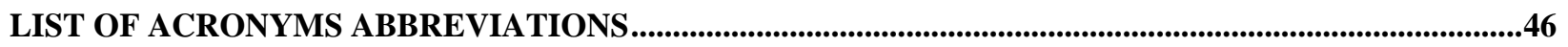

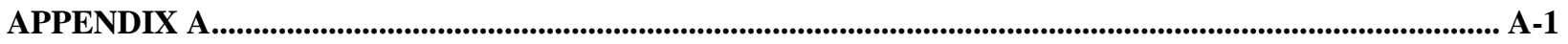

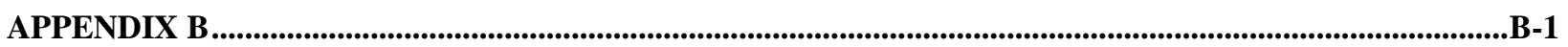




\section{LIST(S) OF GRAPHICAL MATERIALS}

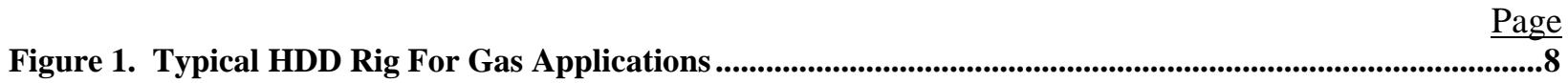

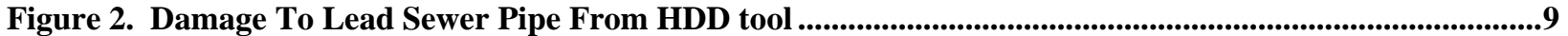

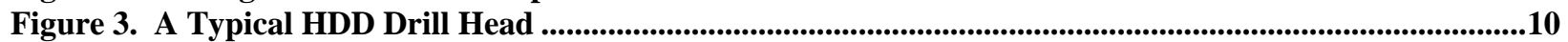

Figure 4. Capacitive Sensor Breadboard With Electrodes In Place.................................................................11

Figure 5. Sensor Breadboard Disassembled ................................................................................................12

Figure 6. Equivalent Circuit Of Capacitive Differential Electrode Pair .......................................................13

Figure 7. Anticipated Current Flow Of Capacitive Configuration .....................................................................14

Figure 8. Block Diagram Of New Sensor Configuration, Asymmetric Axis...................................................15

Figure 9. Equipotential Lines For Symmetric Axis ......................................................................................17

Figure 10. Equipotential Lines Of Symmetric Axis With Obstacle Introduced..................................................18

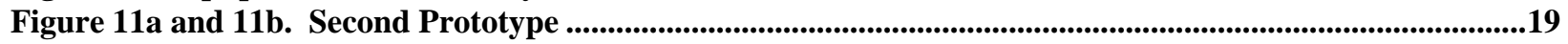

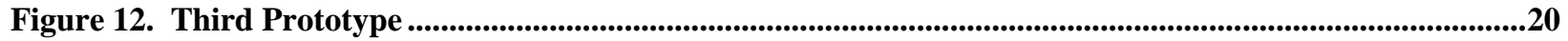

Figure 13. Close-up Of Prototype With Steel Shim Sense Elements ......................................................................20

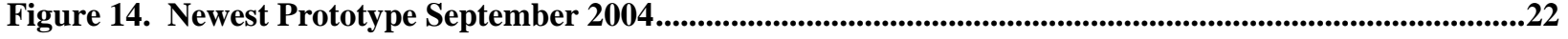

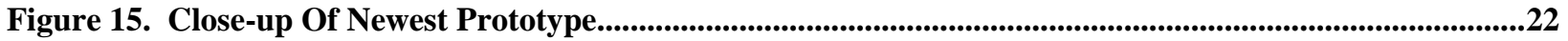

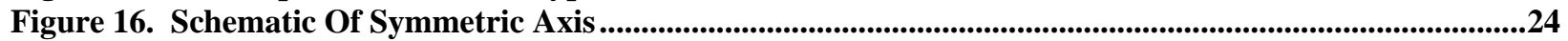

Figure 17. Bench Top Tests With Lexan Obstacle..................................................................................28

Figure 18. Comparison With/Without Copper Guard Tube Connected .............................................................31

Figure 19. Graph of Output vs. Frequency Data from Table 3 ................................................................32

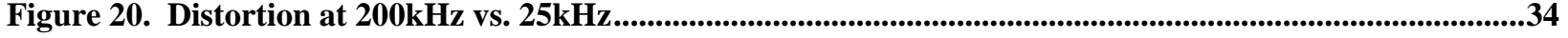

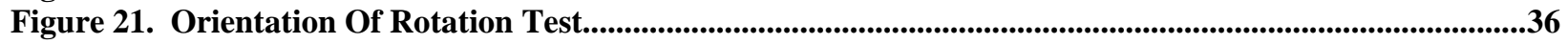

Table 1. Data From Lexan Benchtop Test.........................................................................................................27

Table 2. Data For Tests Comparing Copper And Plastic In Air ........................................................................30

Table 3. Gain Characteristics. $R_{i n}=120 K, R_{f}=2.7 M$ (Case 1$) R_{i n}=12 K, R_{f}=120 K$ (Case 2) ..........................33

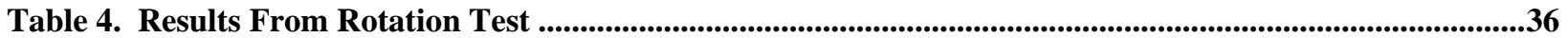




\section{RESEARCH SUMMARY}

Title:

Contractor(s):

DOE Contract Number:

DOE Project Officer:

GTI Project Manager: GTI Principal Investigator:

Report Type: Report Period:

Objective:
Differential Soil Impedance Obstacle Detection Sensor for Use During Pre-Bore of Horizontal Directional Drilling (HDD) Installation

Gas Technology Institute

DE-FC26-02NT41318

Richard Baker

Christopher Ziolkowski

Maximillian J. Kieba

Final Report

March 2002 through September 2004

The objective of this program was to further develop an obstacle detection system for directional drilling rigs by testing a sensor concept in a variety of simulated field conditions. The goal is to provide a simple, robust system that provides the information required to avoid obstacles. This must be done within the size and ruggedness constraints of the HDD equipment.

The installation of plastic gas pipe by the use of HDD has operational and economic advantages. However, with the success in reducing installation costs and the subsequent increased use of HDD, crowded utility easements have become more common and the potential for underground contact with other utilities or obstacles has risen dramatically. Some related devices in development use GPR for sensing. Not only does GPR have range issues, but it also behaves particularly poorly in wet soil conditions.

The GTI DIOD device is designed to address the issues of GPR devices. This sensor utilizes a differential soil impedance measurement technique that will be sensitive to the presence of plastic and ceramic, as well as metallic obstacles. The system will use a simple sensor incorporated into the drill head. The impedance of the soil will be measured with a low frequency signal injected through the drill head itself. The sensor will provide range and direction data for obstacles near the HDD head. Imaging obstacles is not within the scope of this work, as it would require a more elaborate sensor than is practical within the HDD head. 


\section{EXECUTIVE SUMMARY}

The North American gas industry is increasing its usage of guided directional drilling for the installation of gas services and mains. This increased usage is limited by an increased awareness of the hazards associated with drill head collision with buried utility lines such as gas, electric power, water, telephone and sewer. Users of guided drilling equipment, the customers they serve, and the owners of buried utility lines would all benefit from the development of sensing technology that could help avoid unintentional contact with buried obstacles.

GTI has kept abreast of recent developments in proximity sensing and ranging. GTI also maintains a dialogue with the natural gas industry through various advisory groups. This feedback provided a set of criteria for an obstacle detection system. These define the constraints on the cost and complexity of any system to be deployed in an underground construction environment.

The obstacle detection system developed in this project utilizes an impedance sensing technique. This technique can resolve small changes in the impedance of the surrounding environment caused by objects of varying resistive and dielectric properties. Plastic pipe and ceramic conduits represent discontinuities in the soil that should be easily discernable. The sensor would simply be an array of electrodes around the drill head; no additional sensors are required above ground. The body of the drill itself is used to launch the sensing signal into the soil, eliminating any blind spot ahead of the drill. The sensing signal is in the frequency range below $500 \mathrm{kHz}$, avoiding the attenuation issues associated with Ground Penetrating Radar operating in the range above $100 \mathrm{MHz}$.

Simple signal processing and multiplexing will be used to determine the direction and range of an obstacle. The goal is to detect and avoid the obstacle, not to image it, eliminating the need for high frequency time-of-flight signal processing. The normal rotation of the drill head will be utilized to scan the vicinity of the head for obstacles. The array could also be used to passively sense the $60 \mathrm{~Hz}$ signatures radiated from buried power lines. 


\section{INTRODUCTION}

This project focused on the development of technology to improve the reliability and safety of gas distribution systems and construction methods. The objective was to further develop an obstacle detection system for directional drilling rigs by testing a sensor concept in a variety of simulated field conditions.

GTI has been involved in developing new technologies for guided directional drilling since 1984 . GTI supported the conception and commercialization of new products that made horizontal directional drilling (HDD) an increasingly growing practice in the gas distribution industry. In the 1980s, several manufacturers developed new hardware and methods for guided horizontal drilling for service installation applications: gas line services, electrical and cable installations, water and sewer lines, and telephone systems. Consequently, today there are many manufacturers and users of horizontal directional drilling equipment worldwide. In North America, GTI-patented technology is present on about $70 \%$ of all newly manufactured HDD equipment (Figure 1).

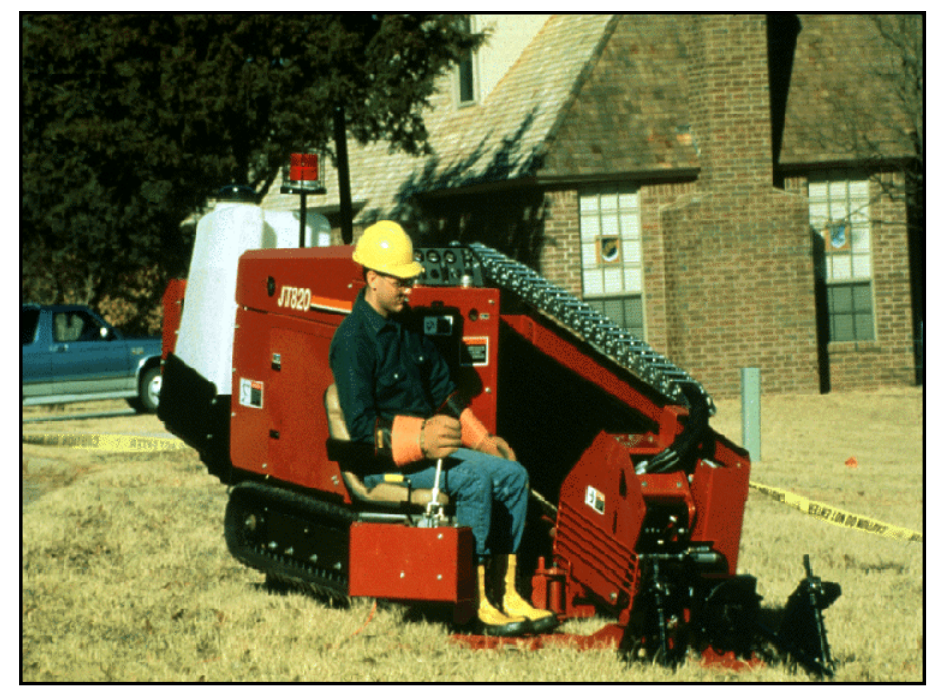

Figure 1. Typical HDD Rig For Gas Applications

With the success in reducing installation costs and the subsequent increased use of HDD, crowded utility easements have become more common and the potential for underground contact with other utilities or obstacles has risen dramatically. Over the past few years, there have been a few extreme incidents of damage resulting from drill collisions with buried facilities.

In addition to dramatic incidents, there are thousands of other utility strikes on gas, electric, telecommunications, water, and sewer lines that occur on a yearly basis. Taken together, these examples illustrate the problems for guided drilling equipment and the need for obstacle detection. For the gas 
industry, one of the most serious situations occur when a guided drilling head or back reamer penetrates a residential sewer line, and a plastic gas pipe is then inadvertently installed through the sewer line. Later, when the sewer becomes clogged, a sewer-cleaning device can cut through the live gas line, releasing natural gas into the sewer and potentially releasing a flammable gas mixture in adjacent buildings (Figure 2). Several gas companies have experienced this type of incident.

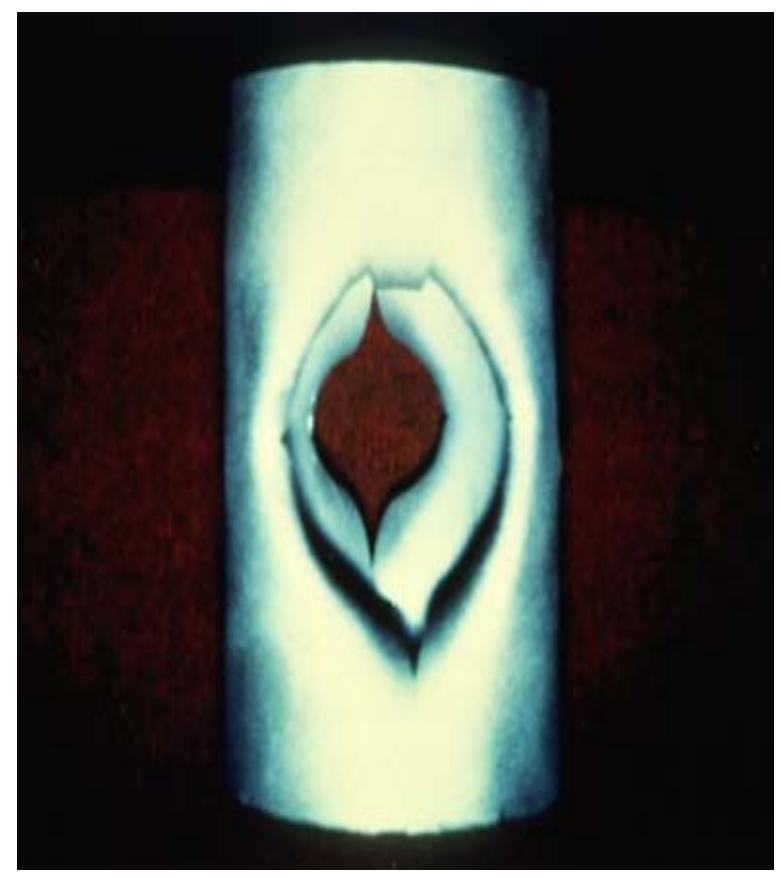

Figure 2. Damage To Lead Sewer Pipe From HDD tool 


\section{EXPERIMENTAL}

The sensor configuration went through several iterations throughout the life of the project since the initial proposed configuration. Certain aspects of the sensor design remained consistent regardless of the method used to inject the signal into the soil. The basic shape and construction of the drill head dictate constraints to the design. In all cases the drill blade, or tip, was used to inject an electrical signal into the soil ahead of the drill. This strategy was adopted to eliminate any blind spot dead ahead. In all cases the rotation of the drill head would be used to scan the surrounding volume for obstacles. Some discussion of the original, capacitive, sensor concept is provided to illustrate both the common issues and the reasons for changing the approach during the project.

The initial proposed configuration for a capacitive tomography sensor consisted of a series of electrodes distributed circumferentially about the drill head just aft of the blade. Figure 3 shows the typical structure geometry for a directional drill head. The blade itself is used to inject the signal into the soil ahead of the drill. The anticipated embodiment is four equally spaced electrodes. Each diametrically opposed pair of electrodes being the differential sense elements of one sensing bridge.

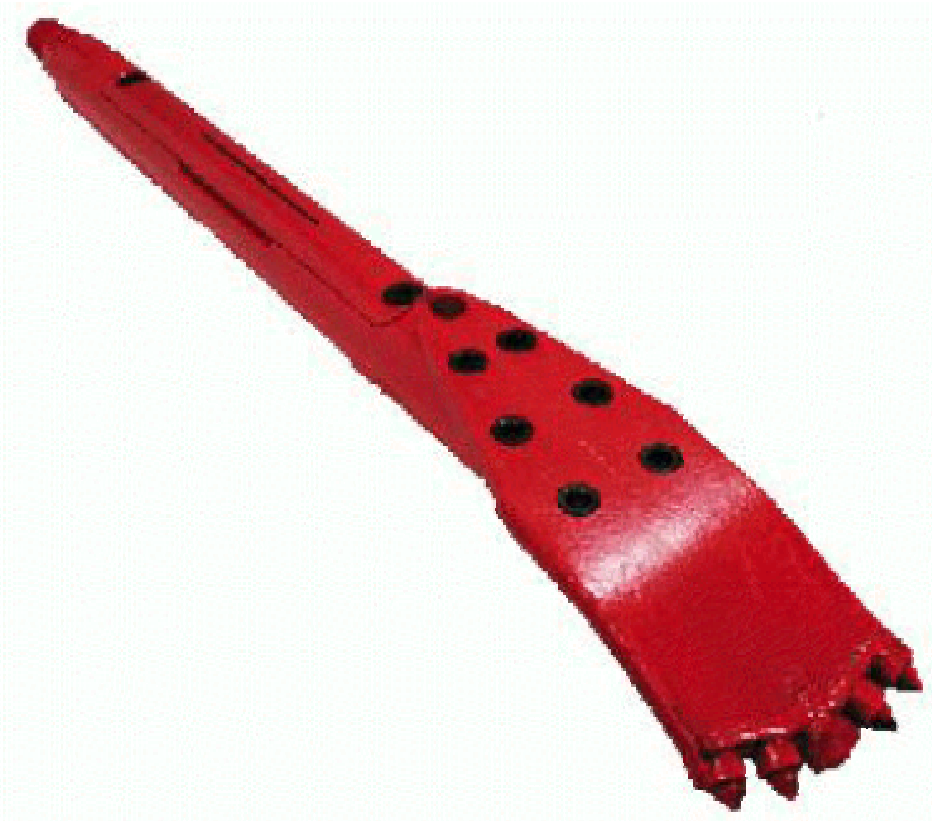

Figure 3. A Typical HDD Drill Head 
Figure 4 shows the arrangement of the sense electrodes on the original capacitive prototype. The opposed pairs of electrodes provide two orthogonal axes over which the soil impedance can be measured. The angle of the drill blade will cause an asymmetry in the distribution of signal current. The leading edge, or tip, of the prototype is simply an angled cylinder. A blade could also be bolted on to the elliptical face of the tip to simulate varieties of drill heads used in the field.

This arrangement of two orthogonal bridge sensors yields two channels of obstacle detection data. The symmetric channel will be most sensitive to objects that are off center with respect to the drill path. The asymmetric channel will be most sensitive to objects directly in the drill path. The exploitation of the tool tip and its asymmetry to prevent a blind spot dead ahead of the sensor is a unique feature of this technology. With other sensor technologies, such as GPR, the metallic mass of the tool tip is a substantial obstacle to forward sensing.

The data fusion of these two channels can be used to sense extended objects such as pipes in the drill path. In order to use the normal drill rotation to scan the vicinity of the drill head a third channel of orientation data is necessary. A tilt sensor will be required on the drill head to provide the instantaneous angle between sensing electrodes and the "down” direction.

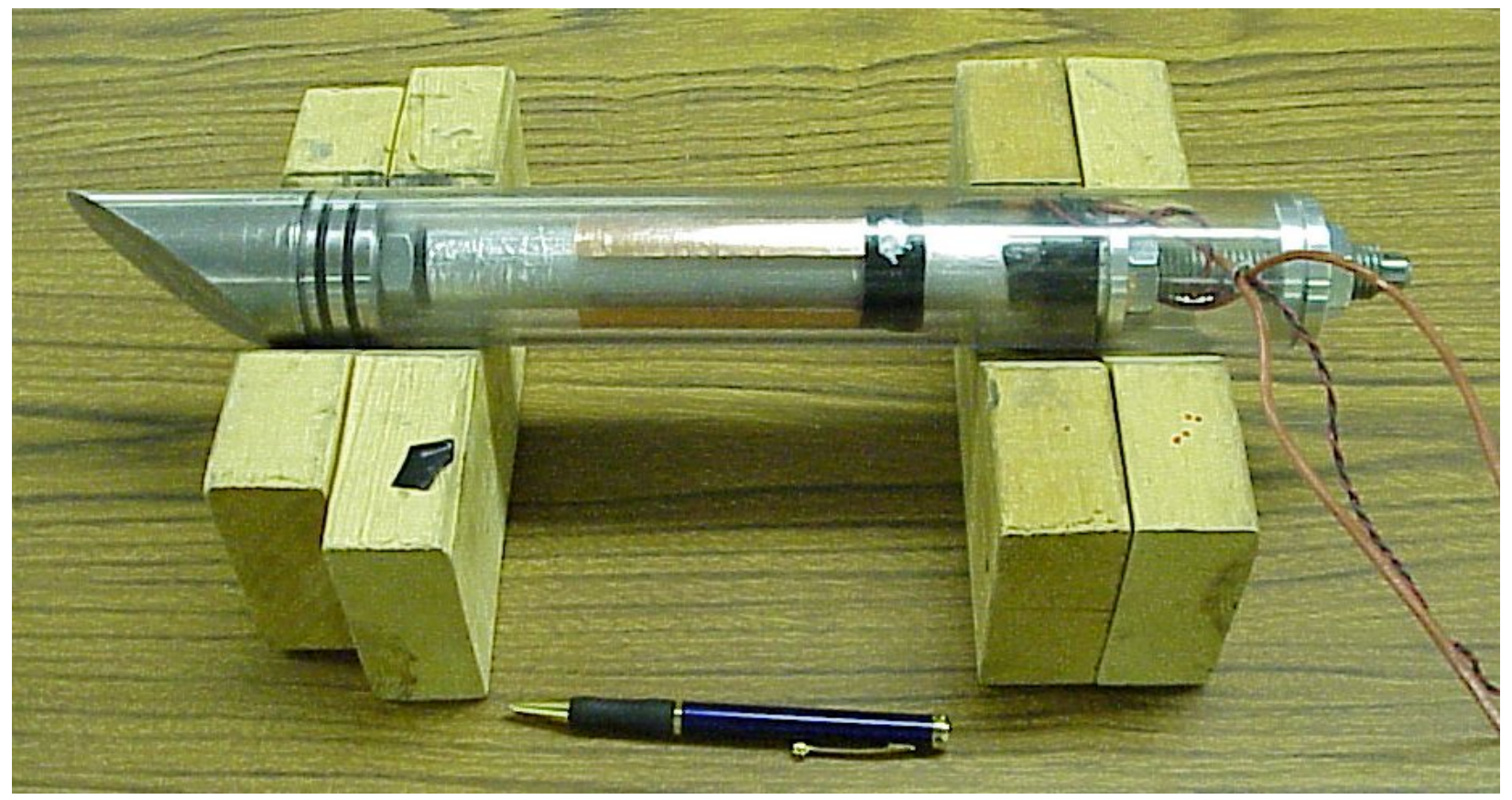

Figure 4. Capacitive Sensor Breadboard With Electrodes In Place 
Figure 5 shows the disassembled capacitive prototype prior to applying the electrodes. The sensing electrodes are capacitively coupled to the soil in this earlier version of the sensor. The outermost lexan tube prevents the sense electrodes from shorting directly to the soil and generally protects the internal electronics. The inner lexan tube carries the sense electrodes on its outer surface, in proximity with but not touching the soil. A third tube slides directly over the threaded rod, within the one carrying the sense electrodes. This innermost tube is the electrode labeled “drive” in Figure 6.

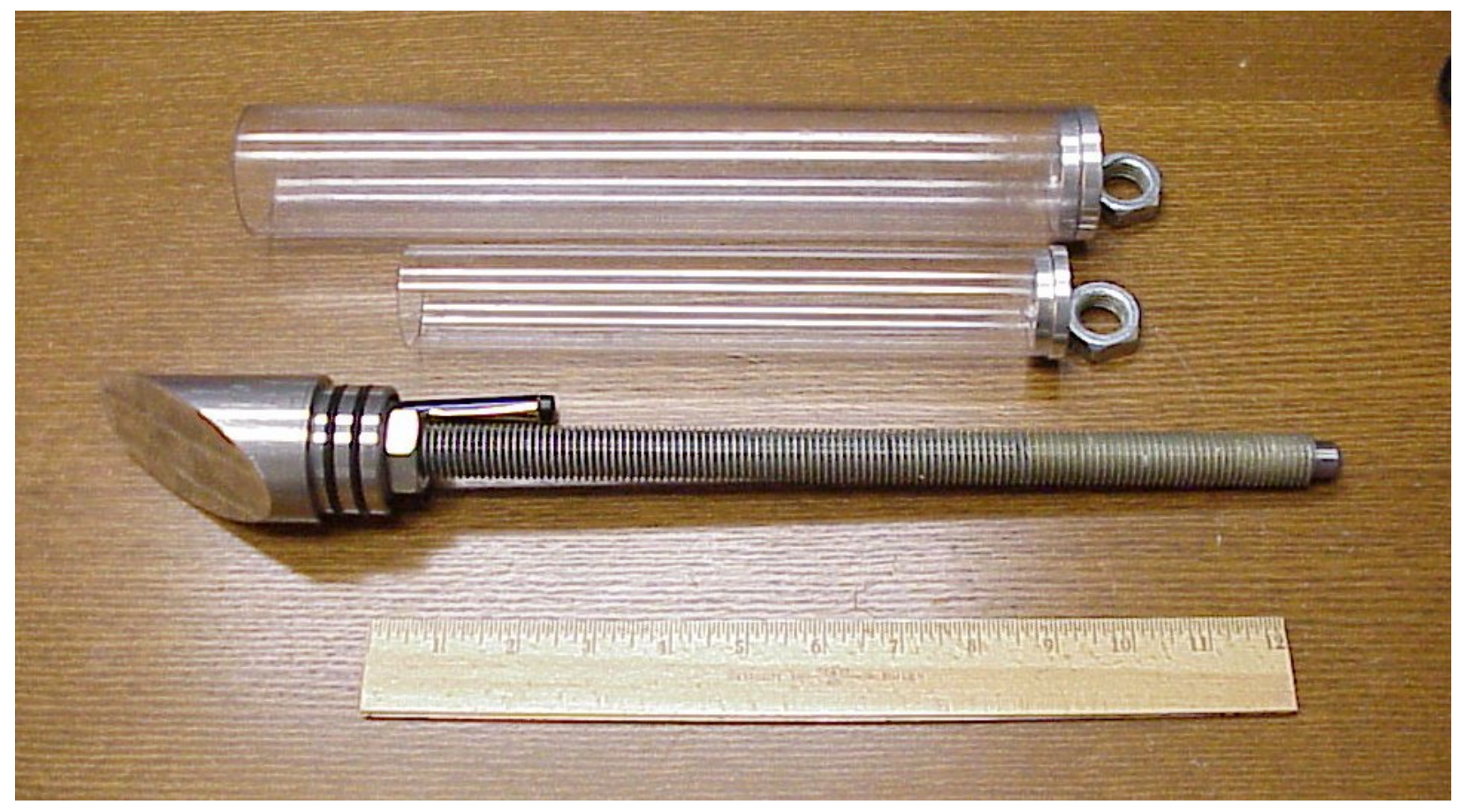

Figure 5. Sensor Breadboard Disassembled

The return path for the sensing current is capacitive, passing through both the sensing electrodes and a "drive" electrode located behind them. The anticipated current paths are shown in Figure 7.

The circuitry to support this low number of channels and modest frequency requirements will be straightforward and inexpensive. Since the sensing signal is injected by direct contact the device can operate at multiple frequencies. This is in contrast to GPR, where each frequency of operation requires a tuned antenna. This broadband sensitivity also allows the sense elements to detect $60 \mathrm{~Hz}$ or other active signatures that may radiate from buried infrastructure. 


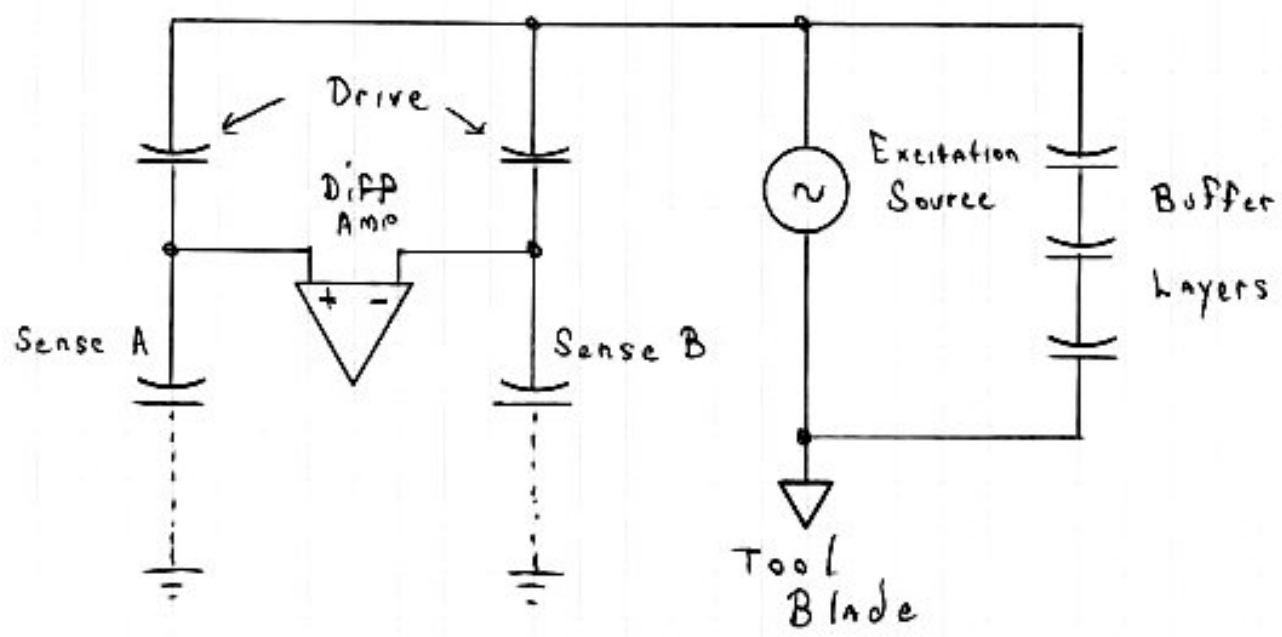

Figure 6. Equivalent Circuit Of Capacitive Differential Electrode Pair

In relation to the equivalent circuit of Figure 6, the drill tip corresponds to the "tool blade”. The drill tip is one terminal of the signal generator providing the bridge excitation signal. It was thought the intimate contact between the drill tip and the soil would ensure a reasonable amount of excitation current was injected into the soil. The "drive" electrode is the metallic cylinder at the center of the other lexan tubes in Figure 4. The drive electrode consists of a lexan tube that is covered with aluminum tape and wiring brought out. The copper metal strips in the foreground are the sense electrodes, mounted on an intermediate lexan tube between the drive electrode and the outside world.

There are four sense electrodes equally spaced about the circumference. Diametrically opposite pairs are wired together to form the impedance bridge. This arrangement forms a threelayer capacitor where the third plate is the soil outside of the largest lexan tube. The soil is in resistive contact with the tool tip as noted above. With reference to the equivalent circuit, this three-layer capacitor is identical to two capacitors in series, which make up each leg of the bridge circuit. 

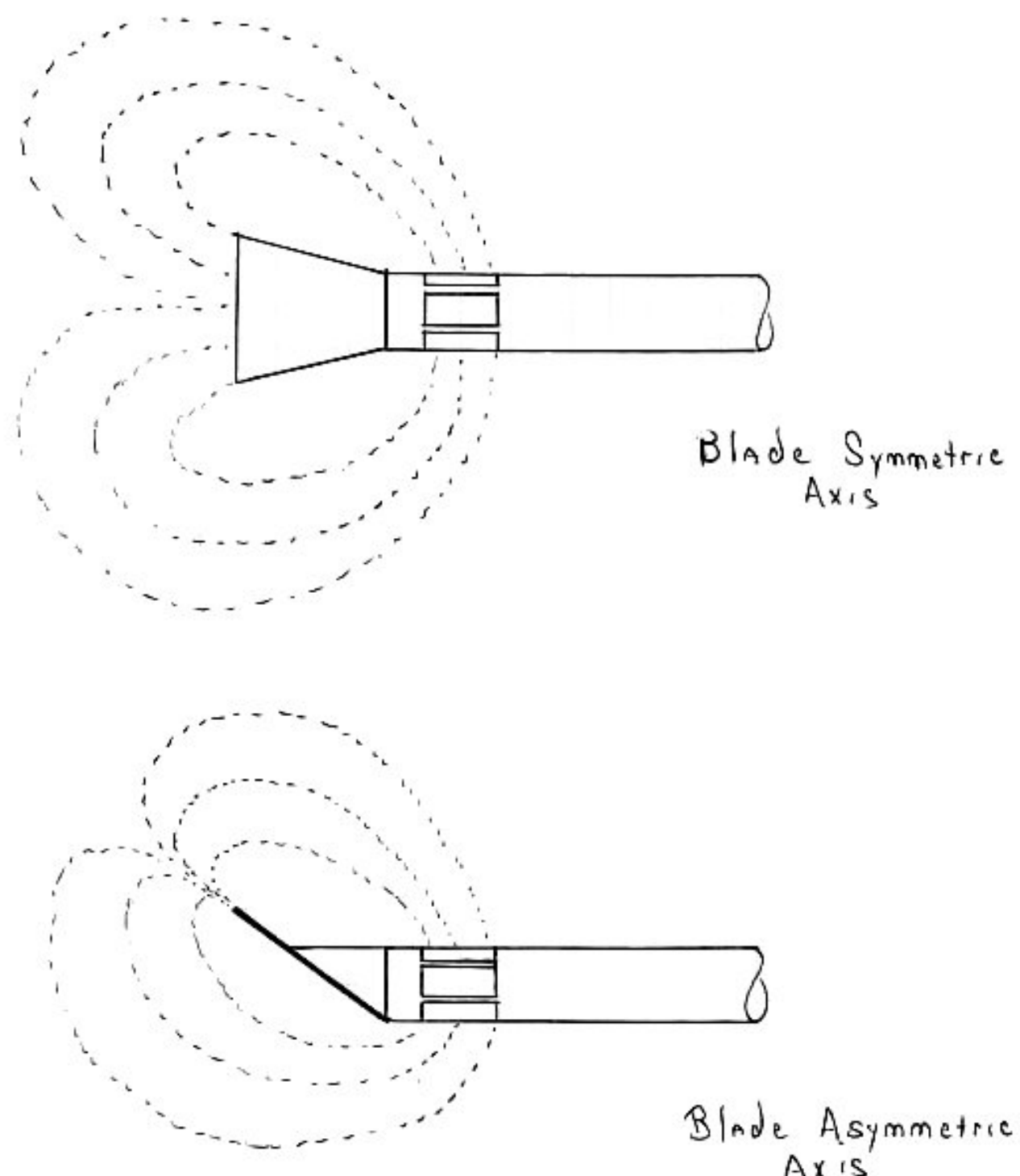

Figure 7. Anticipated Current Flow Of Capacitive Configuration

Figure 7 shows the anticipated current flow of the capacitive configuration as described in the original proposal. Keep in mind there is a layer of air and a sleeve of lexan between the sense elements and the soil. The pod with capacitive sense elements is about 18" in length. It was realized if you then add several hundred feet of metal pipe behind the pod, such as drill stems during an HDD installation, the current flow would likely be from the drill pipe as well as the tip. This was cause for concern of the effectiveness of the design, resulting in a change of configuration. 
The next sensor configuration was based on resistive rather than capacitive tomography. With this setup, the signal current was intentionally injected at the tool blade and collected by the drill pipe. Instead of having the sense elements separated from the soil with a section of air and the lexan sleeve to create a capacitor with the soil, the sense elements protruded through the lexan sleeve to make resistive contact with the soil. These contacts are depicted as the rounded protrusions on the sides of the drill body in Figure 8. They were located on an insulating sleeve that separated the drill tip from the drill pipe.

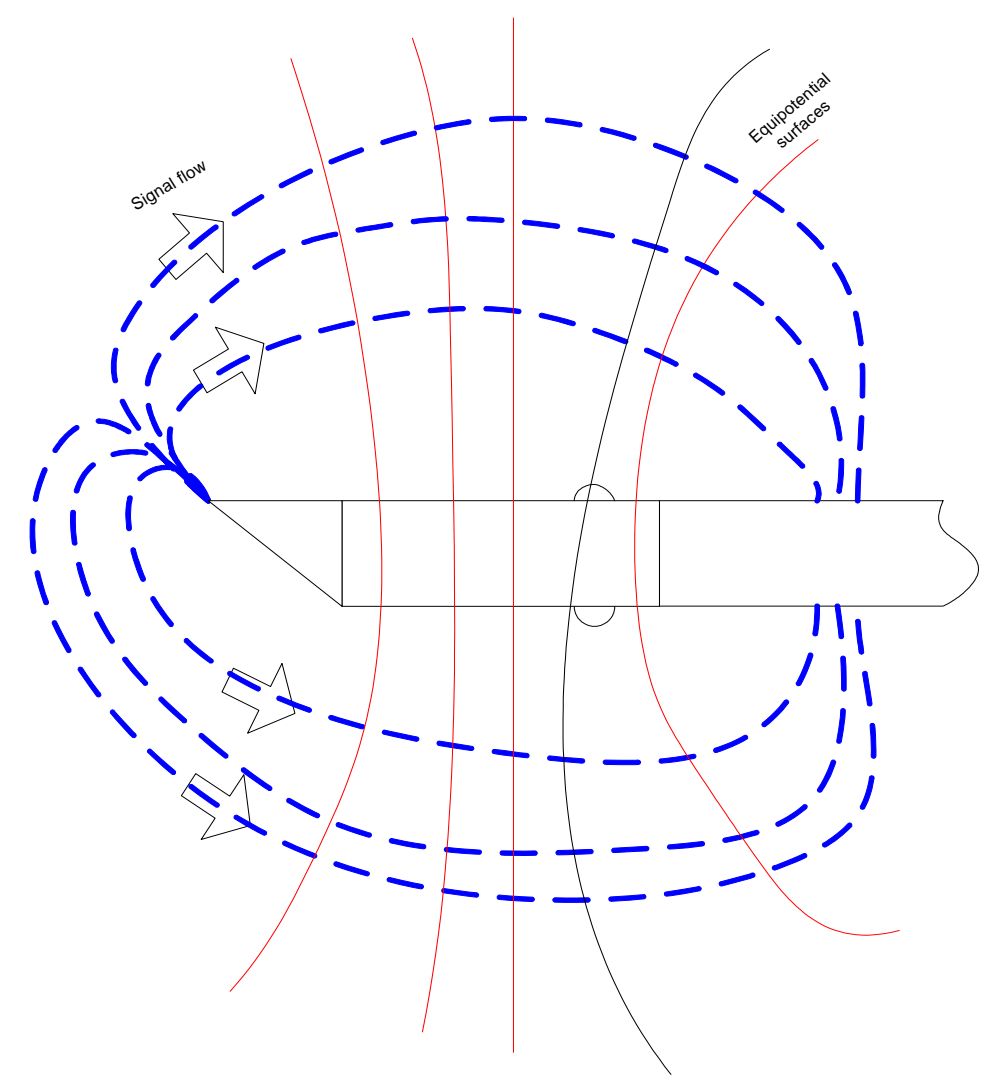

Figure 8. Block Diagram Of New Sensor Configuration, Asymmetric Axis

The prototype resistive contact elements were four screws placed equidistant around the circumference of the lexan. These contacts would probably be made flush with the drill body as prototyping progressed. The concern was that any projection would be subjected to wear in the normal environment of a horizontal directional drill. The contacts must also be sensitive to $60 \mathrm{~Hz}$ currents and other known infrastructure signatures. 
Figure 8 shows the two elements measuring across the asymmetric axis of the tool blade. There were another two screws used to measure across the symmetric axis. The signal current passing from the drill tip to the drill pipe generated voltage potentials along its path. The contacts directly sensed these potentials. The signal was detected by taking the voltage difference between opposed pairs of these contact points. The signal was then amplified and filtered to get a signal that could be measured.

Keep in mind the field lines shown in these figures are the desired field lines for a successful design. These figures are only sketches to provide a visual explanation of the characteristics of the configuration. It was determined at a later date that the use of a finite element-modeling program would better approximate the field lines that would be generated.

In a perfectly homogenous soil, the amplitude of the signal after the filtering would have a reasonably steady value. Notice in Figure 8 that the one equipotential line does not pass directly through the sense contacts at the same point. Along the asymmetric axis, the upper current path is slightly shorter. It is anticipated that there should be a small differential voltage across the drill body in this plane, caused by the asymmetry. As a result, the equipotential is slightly askew. This is why when comparing values for the two axes, the values for the asymmetric axis should be slightly unbalanced when compared to the symmetric axis in a homogenous soil. For comparison, view how the symmetric axis would most likely look in Figure 9. Contacts on opposite sides of this symmetric axis should see very little differential voltage in homogenous soil. 


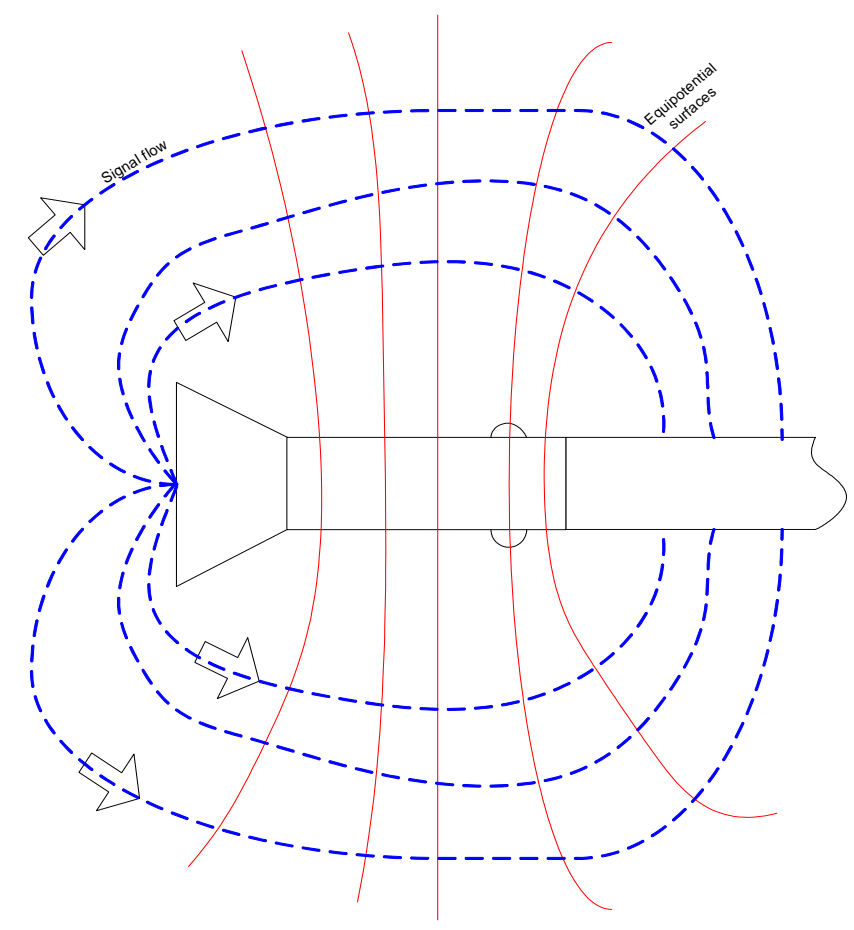

Figure 9. Equipotential Lines For Symmetric Axis

Any inclusions in the soil change the potential distribution, therefore changing the differential voltage. Figure 10 shows the distribution when an obstacle is introduced. Take note of the equipotential line going through the sense elements. When an obstacle is introduced, the current path on that side now becomes longer and slightly distorted. This affects the equipotential line, causing an imbalance to be detected by the signal conditioning electronics. 


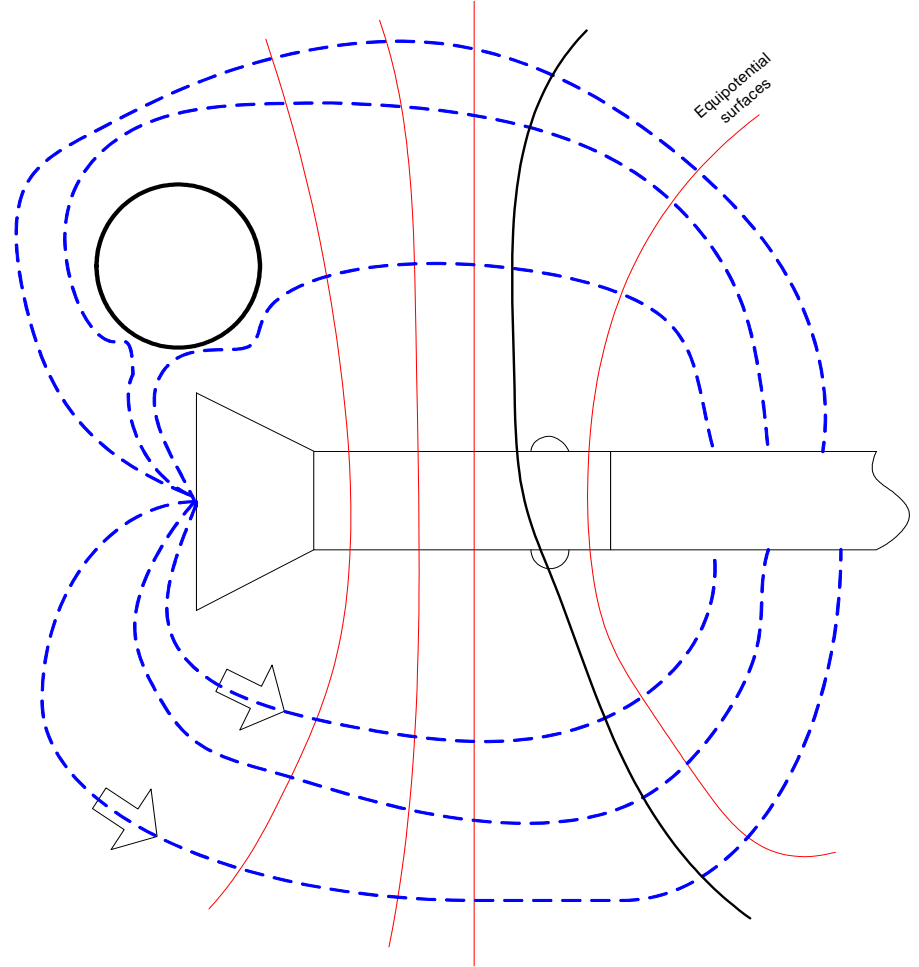

Figure 10. Equipotential Lines Of Symmetric Axis With Obstacle Introduced

The version of the prototype based on resistive tomography is shown in Figure 11. The tool blade tip and the length of the first section of lexan remained the same. The screws that acted as the sensing elements can be seen protruding from the lexan just before the first section of PVC pipe. The section of PVC connects the lexan portion to the steel pipe portion representing the drill pipe. Another PVC section connects the end of the steel pipe, representing a portion of drill stem, to another portion of lexan to provide an exit point for the cabling. Finally, the metal end cap of the sensor attaches to the end of the small portion of lexan, keeping the metal cap, threaded rod, and drill tip electrically isolated from the drill pipe. The PVC coupling pieces needed to be added because the lexan pipe does not have the same ID and wall thickness as standard PVC or steel pipe. 

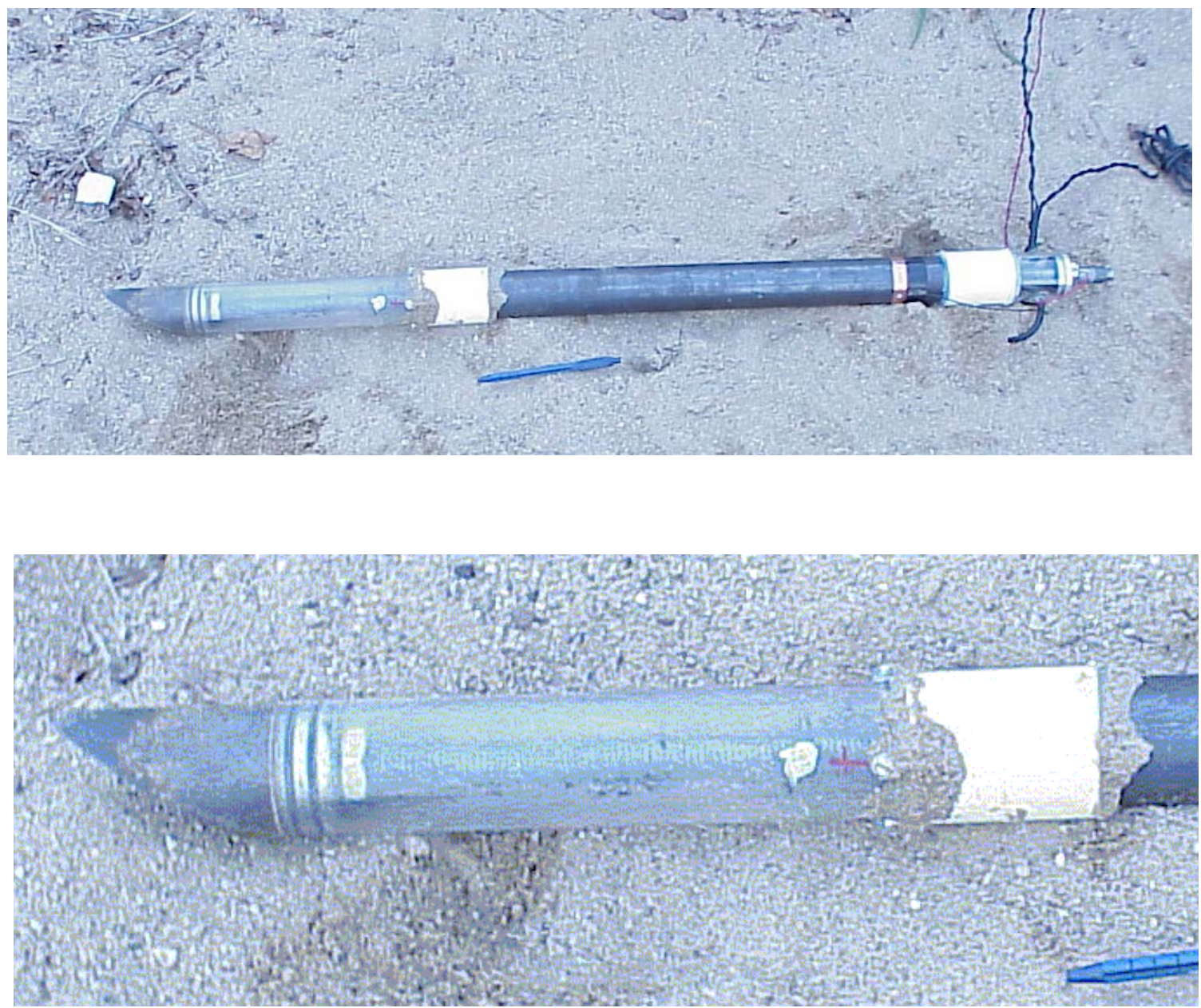

Figure 11a and 11b. Second Prototype

The source excitation signal was applied between the steel pipe and the tool blade tip. The tool tip was connected to the threaded rod, creating a coaxial feed for the excitation signal. Because of this, it was thought there was no need for the added buffering layers of the drive tube used with the capacitive configuration. The threaded rod connected the tool blade tip to the end cap. The black miniature coaxial cable is the cabling for the sensing elements. The entire sensor pod was 41.5 ” in total length.

Tests with the version based on resistive tomography had some issues. Most notably, the initial screws used as the sense elements were made of zinc-plated steel. Since this is a different material than the tool blade tip, a potential was created which affected the readings. Another version was made using steel screws and shown in Figure 12. In addition to changing the setscrews, the lexan portion was replaced with PVC to make it easier to assemble/disassemble 
the device. Shielding around the threaded rod portion was also added to keep the signal from bleeding directly to the sense elements.
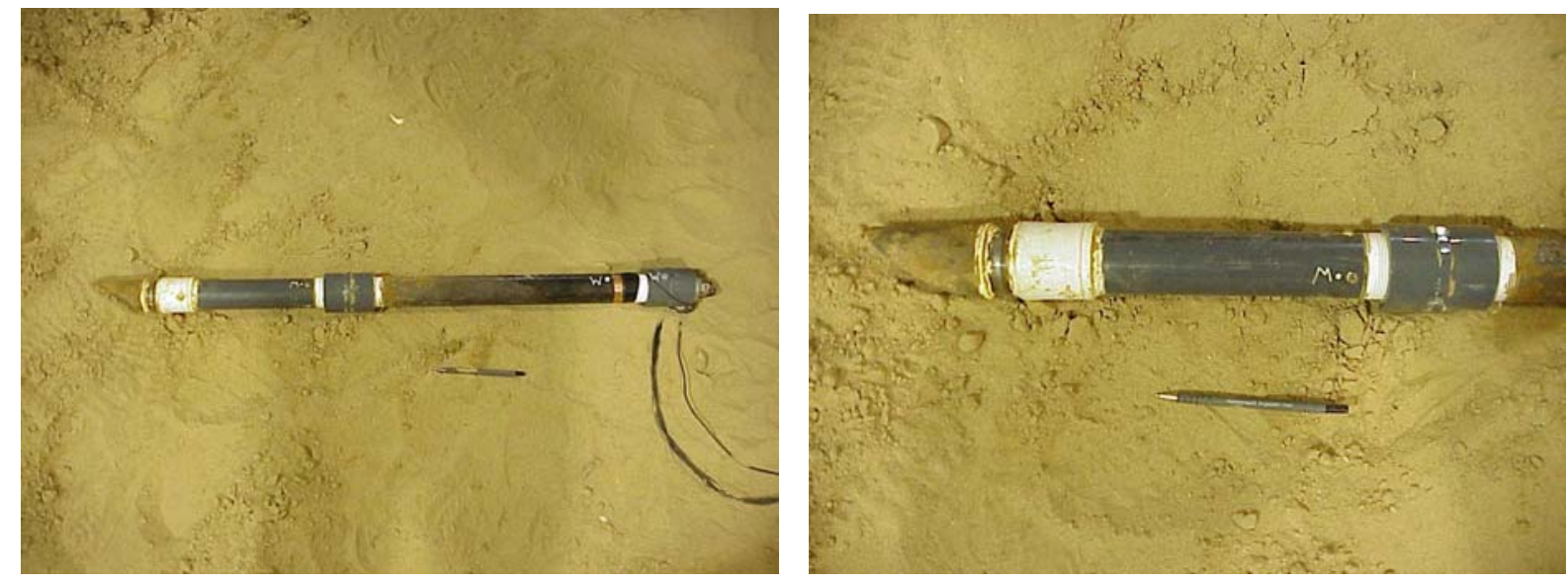

Figure 12. Third Prototype

The version with carbon steel setscrews had pickup issues. It was initially thought that these issues were due to the small surface area of the sense elements. A modification was made to add steel shim stock to the setscrews, thus increasing the surface area of the sense elements. The result is shown in Figure 13.

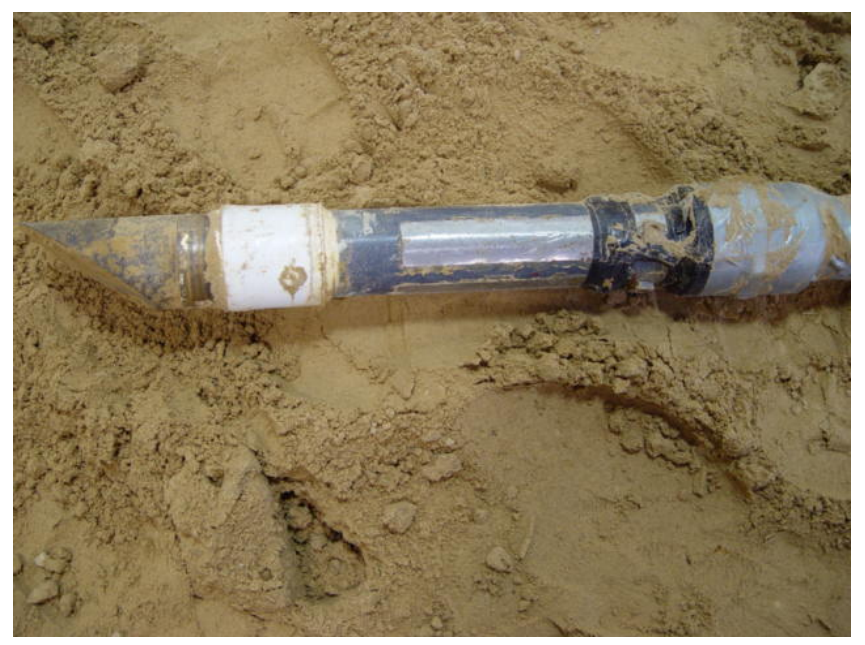

Figure 13. Close-up Of Prototype With Steel Shim Sense Elements 
Adding the shim stock did not improve results. It was apparent there was still a contact issue using the version based on resistive tomography. It was then decided to go with a hybrid version of prototype. A new custom built prototype, shown in Figures 14 and 15, was made which made it easier to assemble/disassemble the unit, made it more waterproof, and included lexan as the outer tube. The new version has the latest drive configuration with current flow from tool tip to drill stem. The pickup went back to a capacitive version, but this time the sense elements were closer to the lexan wall, thus virtually eliminating the added dielectric of air caused by the gap in the previous capacitive pickup version. A copper tube was added to provide additional shielding between sense elements. There were also issues with the version using threaded components, where the portion with sense elements could get misaligned from the drill tip with enough rotation/vibration. The new version used setscrews throughout the sensor to keep the various pieces in line.

Significant advancements were made with the newest sensor. Tests performed with the previous version using steel shim-stock sense elements on the outside of the sensor yielded poor results. Namely, there was a significant contact potential issue contributing to the difficulties in achieving a balanced state in a homogeneous soil condition. There was also poor repeatability of measurements between tests.

The new hybrid prototype (Figures 14 and 15) kept the second drive configuration, but incorporated a capacitive pickup used in the first prototype. The capacitive pickup configuration was abandoned previously because it was also incorporated with a drive configuration which would very likely yield poor results when the long length of steel drill stem was added aft of the sensor during an HDD installation. There were also other issues with sensitivity which prompted a change in both the drive and sense configurations. The change in the drive configuration and conditioning circuitry resolved some of the issues. The contact issues with the sense configuration, though, prompted the desire to change the pickup back to a capacitive setup. 


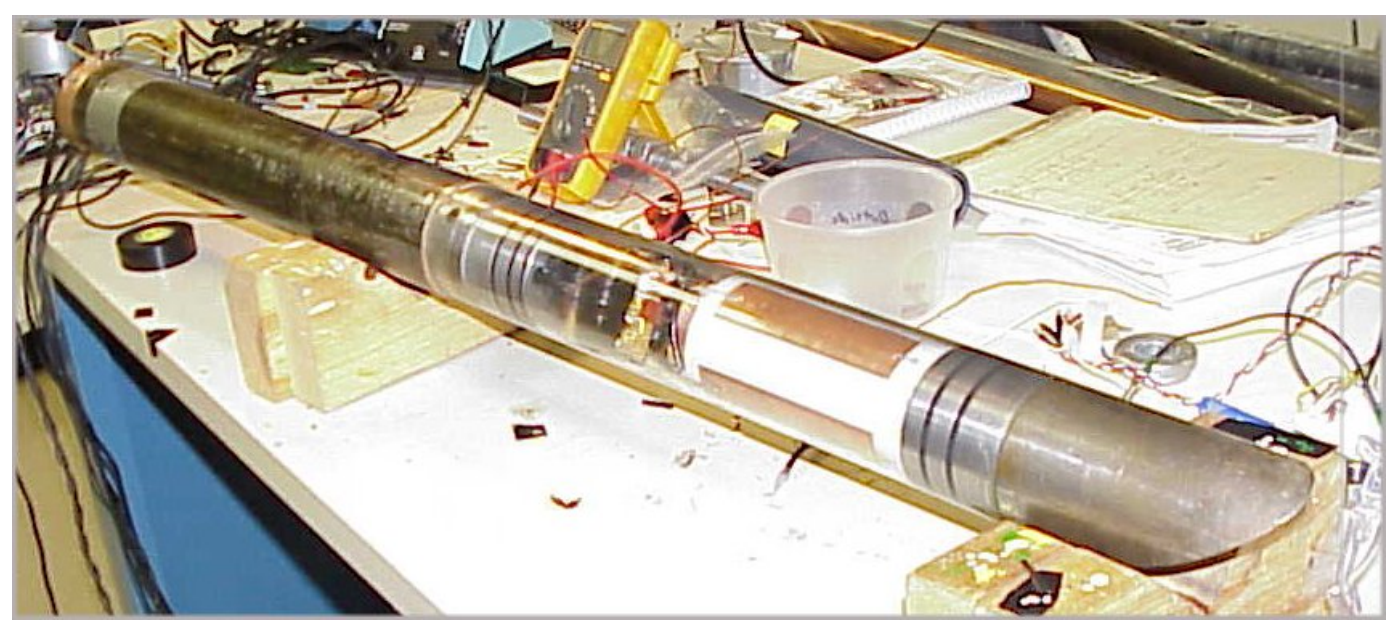

Figure 14. Newest Prototype September 2004

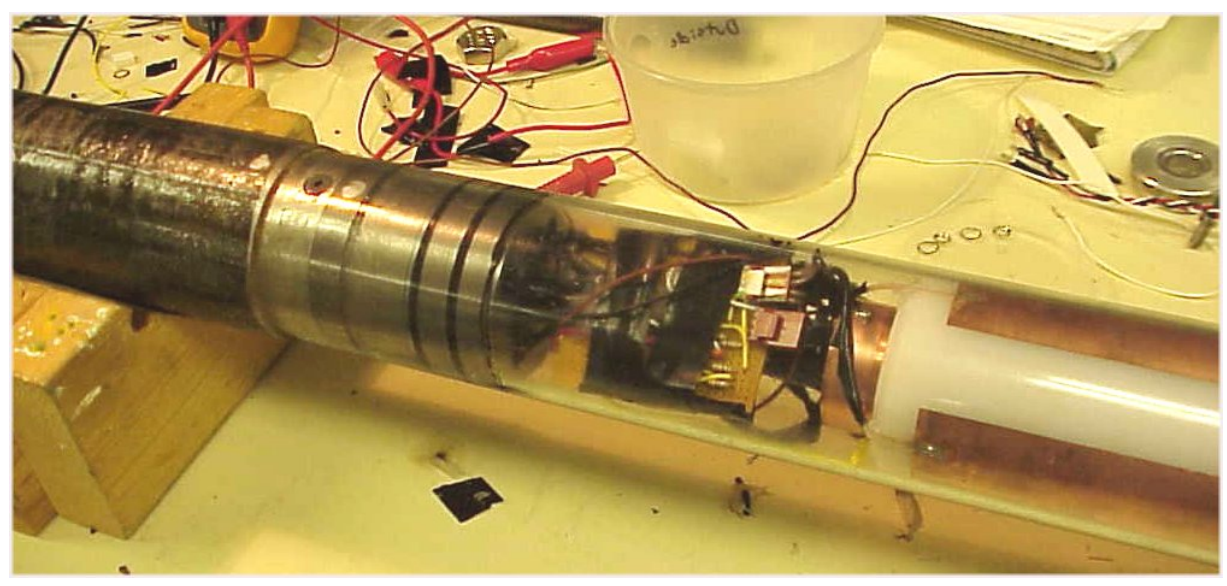

Figure 15. Close-up Of Newest Prototype

A few differences should be noticed between the sensor in Figures 14 and 15 compared to earlier versions. Mechanically, the overall sensor is larger in diameter (2.75” compared to 2”). This is mainly to fit the tolerances of the outer lexan, inner white polyethylene tube, and steel portion. It also allows more space for inclusion of circuitry within the pod. The resulting sensor is not only much cleaner than the previous version (Figure 13), but it is also easier to assemble/disassemble for quick changes to different portions of the pod. Each portion of the sensor is self-contained so it can be removed without significantly changing the rest of the pod.

The sensor was also designed with the intention of it eventually having to be a field-ready prototype. The previous version had too many threaded pieces that could be loosened with 
enough vibration to the pod. This could eventually cause the sense elements to get misaligned from the tool tip. The new version has set screws throughout the different portions of the sensor, so turning the steel portion will rotate all portions equally and keep the sense elements aligned. There are also setscrews going from the lexan to metal portions for this same purpose, as well as a threaded rod going to the tip. The threaded rod remained to more easily allow changes to the overall sensor length. Setscrews through the lexan portion are adequate for lab testing, but some of the load is being transferred to the lexan during rotation. In the final version, the threaded portion will be replaced with a metal piece welded to the tip for added durability, and the sensor made such that the load will transfer through the internal metal portion of the pod.

The sensor was also designed to eliminate the air gap between the sense elements and outer lexan skin. The earlier version with capacitive pickup had a small air gap between elements and lexan. There were concerns that having two dielectric layers, air and lexan, between the sense element plate and virtual plate of the soil could be contributing to some of the sensitivity issues. Now the sense elements are applied to the outer portion of the white polyethylene tube that is friction fit into the outer lexan. The only significant dielectric between the sense plate and the soil is the wall of the lexan tube. (Note: This statement is prior to FE modeling.)

A very significant change was the addition of the copper tube, a portion of which can be seen just after of the white polyethylene tube portion in Figure 15. This copper tube is inserted through the length of the white plastic tube and provides additional shielding for the sense elements. Shielding around the threaded rod portion had already been used to prevent the excitation signal from bleeding directly to the sense elements. The addition of the copper tube provides shielding to prevent "cross-talk" between the sense elements. Having a friction fit between this shielding and the polyethylene carrying the sense plates normalizes the impedance seen by the sense plates. The chance of spurious signals coupling to the non-soil side of the sense elements is greatly reduced.

Initial tests with the new sensor still had the first stage on the bench top breadboard connected by long lengths of mini-coax cable. Results were not good, so it was decided to place the first stage amplifier as close as possible to the sense elements. This is the small board in Figure 15 within the lexan tube. It was also decided to switch the first two stages. The previous version of the schematic had the AD621 differential amplifier as the first stage, followed by the LF412 amplifier stage, and finally the AD630 stage. It was decided to put the LF412 stage first to provide buffering for each of the sense element legs. This also allowed for manipulation of the feedback circuit of the LF412 to insure the maximum gain covers an adequate frequency 
range. The current circuit is shown in Figure 16. The circuit is the same for the asymmetric axis.

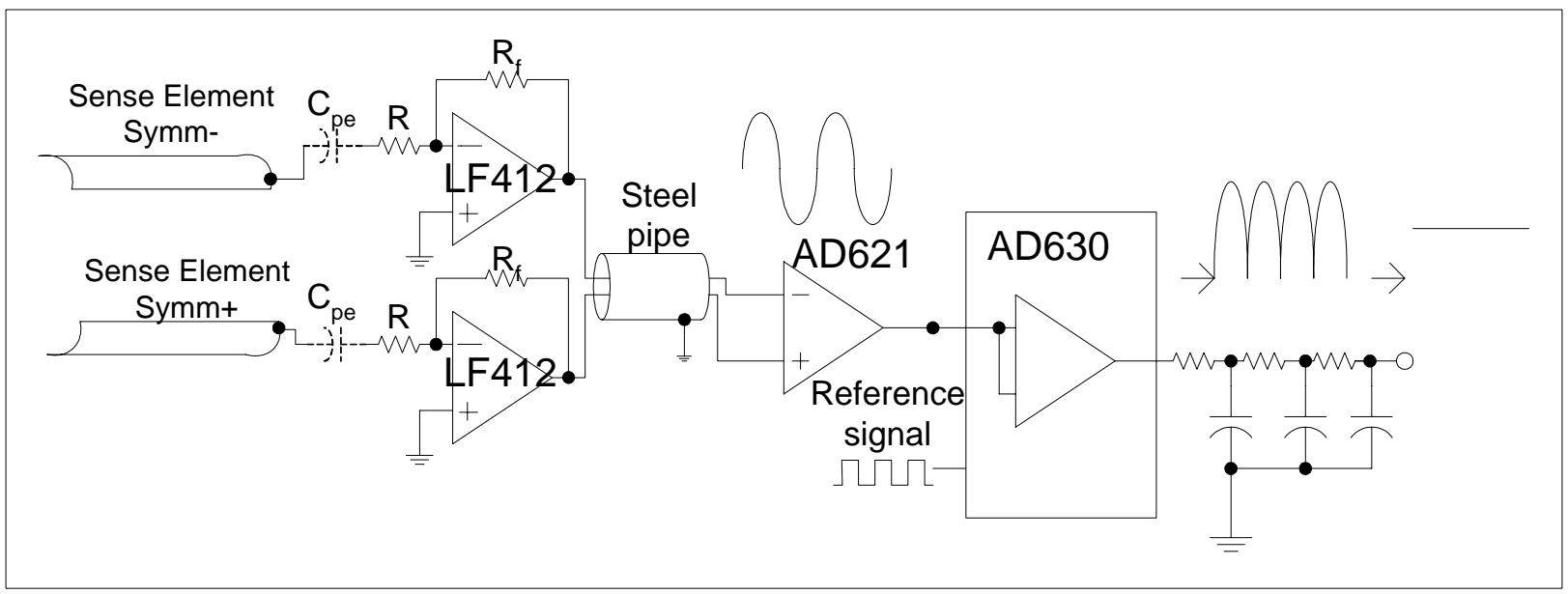

Figure 16. Schematic Of Symmetric Axis

Please note: the following equations were used at the time the newest sensor was created. It was realized later that when making calculations of capacitances through non-homogenous soil conditions, a more complex equation for capacitance is required. Similar to the field line sketches earlier, these equations are left in to provide a visual explanation of the thought process.

$\mathrm{C}_{\mathrm{pe}}$ is a representation of the capacitance between the sense element (plate) and the soil (earth). It was difficult to measure the exact value of this capacitance while the sensor was in the soil, so an approximation was made based on the element size. Each of the elements was 1" $\mathrm{x}$ 4.5”. The dielectric constant of polycarbonate (lexan) is about 3. Using the equation

$$
\mathrm{C}=0.224 *(\mathrm{KA} / \mathrm{d}) *(\mathrm{n}-1)
$$

where $\mathrm{K}=$ dielectric $=3, \mathrm{~A}=$ area in inches $=4.5 \mathrm{in}^{2}$, $\mathrm{d}=$ distance between plates (wall thickness of lexan=0.1279in), $n=$ number of plates (2)

yielded $\mathbf{C}=\mathbf{2 3 . 6 4} \mathbf{p F}$. The aim was for reasonable gain over the frequency range of 100-300 kHz. Earlier tests were performed at $50 \mathrm{kHz}$, so the R-value would be

$$
\mathrm{R}=1 /\left(2 \pi \mathrm{fC} \mathrm{pe}_{\mathrm{pe}}\right)=1 /(2 * \pi * 50 \mathrm{kHz} * 23.64 \mathrm{pF})=\mathbf{1 3 4 . 6} \mathbf{k} \Omega
$$


For a gain of 10, the desired feedback resistor, Rf, is 10 times the series impedance of the input capacitance plus the input resistance.

$$
\mathrm{R}_{\mathrm{f}}=10\left(\mathrm{R}+\left(1 /\left(2 * \pi * \mathrm{f}^{*} \mathrm{C}_{\mathrm{pe}}\right)\right)\right)=\mathbf{2 . 6 9 3 M} \Omega
$$

The closest and most convenient resistors were $120 \mathrm{k}$ and $2.7 \mathrm{M}$. There is a difficulty with obtaining a feedback capacitor to attenuate the frequencies above $300 \mathrm{kHz}$. The value of $\mathrm{C}_{\mathrm{f}}$ is given by the following equation.

$$
\mathrm{C}_{\mathrm{f}}=1 /(2 * \pi * 300 \mathrm{kHz} * 2.7 \mathrm{M} \Omega)
$$

This yielded a C of $0.19 \mathrm{pF}$. Anything available commercially is too large, so the feedback capacitor wasn't included. It was concluded, and later demonstrated, that the gain bandwidth (GBW) product of the amplifier would provide a high frequency roll-off.

The first tests with the board inside the pod showed 1.5MHz noise. De-coupling capacitors between power and ground were added to match those on the bench breadboard.

Initial tests with the resistors above did not yield maximum gain for the desired frequency range of $100-300 \mathrm{kHz}$. The gain was only good up to a frequency of about $30 \mathrm{kHz}$ with no apparent low range. The first thought was that the $\mathrm{C}_{\mathrm{pe}}$ value was different than the calculated estimate. Adjusting the resistor values to $12 \mathrm{k} / 270 \mathrm{k}$ did allow the gain to work for the desired frequency range, but tests on the signal showed a sloping issue with the AD621. After more testing, it was decided that the best results occurred at $25 \mathrm{kHz}$ and going back to resistors of $120 \mathrm{k}$ and 2.7M. Data and results explaining the situation further are given in the "Results and Discussion” Section.

With the addition of the copper guard tube, the first stage inside the sensor, and the adjustment of resistor values, test results were much better. When tested on a bench top (background medium is air), an obstacle placed near each sense element of the symmetric axis caused an equal and opposite imbalance depending on the sense element compromised. In comparing an equally sized plastic and copper obstacle, the copper caused more of an imbalance. Again, since the background medium was air, this is expected. It is expected with a background medium of soil, the opposite would be true. Data is shown in the Results and Discussion section.

The sensor was then tested in the loam test bed. The first test was done with the permanent 4" PE pipe. The permanent pipe is about 3.5' deep. The sensor was placed so the tip was about 1' foot above and about 1-2' away from the pipe. Again, an equal and opposite imbalance was seen depending on the sense element orientation. 
Testing was then performed with a smaller section of 4" PE pipe as an obstacle and with the sensor rotated 360 degrees to determine the field of view of the sense elements. When one of the elements was pointing directly at the pipe, the sensor bridge showed its maximum imbalance, as expected. When a given pair of elements was oriented parallel to the pipe the imbalance was minimized, again, as expected. The elements had a sensing range of approximately $+/-45$ degrees, or one quadrant each.

The loam tests were not perfect, however. There did appear to be some contact issues while the pod was being rotated. The contact issues weren't nearly as pronounced as with the setup using the shim stock on the outside of the sensor tube, but enough to keep notice. More details and data are given in "Results and Discussion". 


\section{RESULTS AND DISCUSSION}

The most recent changes to the configuration, including switching the first stage to the LF412, modifying the resistor values, placing the first stage close to the sense elements, and most importantly including the copper tube as shielding between sense elements, significantly improved results from previous designs.

The first test with the new configuration was performed on a bench top. This test was without the initial balanced state set (i.e. for balance the mean level output of the AD630 should be zero). Keep in mind on a bench top with no target obstacle present, it is difficult to assume there is balance; the sensor could be picking up any large obstacle nearby (such as another work bench or metal cabinet). Initially, adjusting the phase of the excitation signal relative to the reference signal produced the balanced state. This test was to confirm that regardless of the initial state, an obstacle affected each sensor of the symmetric axis equally. After the obstacle tests, the reading should return to its initial value.

Data is shown in Table 1. The test was performed with a $25 \mathrm{kHz}, 20 \mathrm{Vpp}$ excitation signal. A 2.75” OD lexan tube was introduced as the obstacle to determine if it equally affected both sides of the symmetric axis.

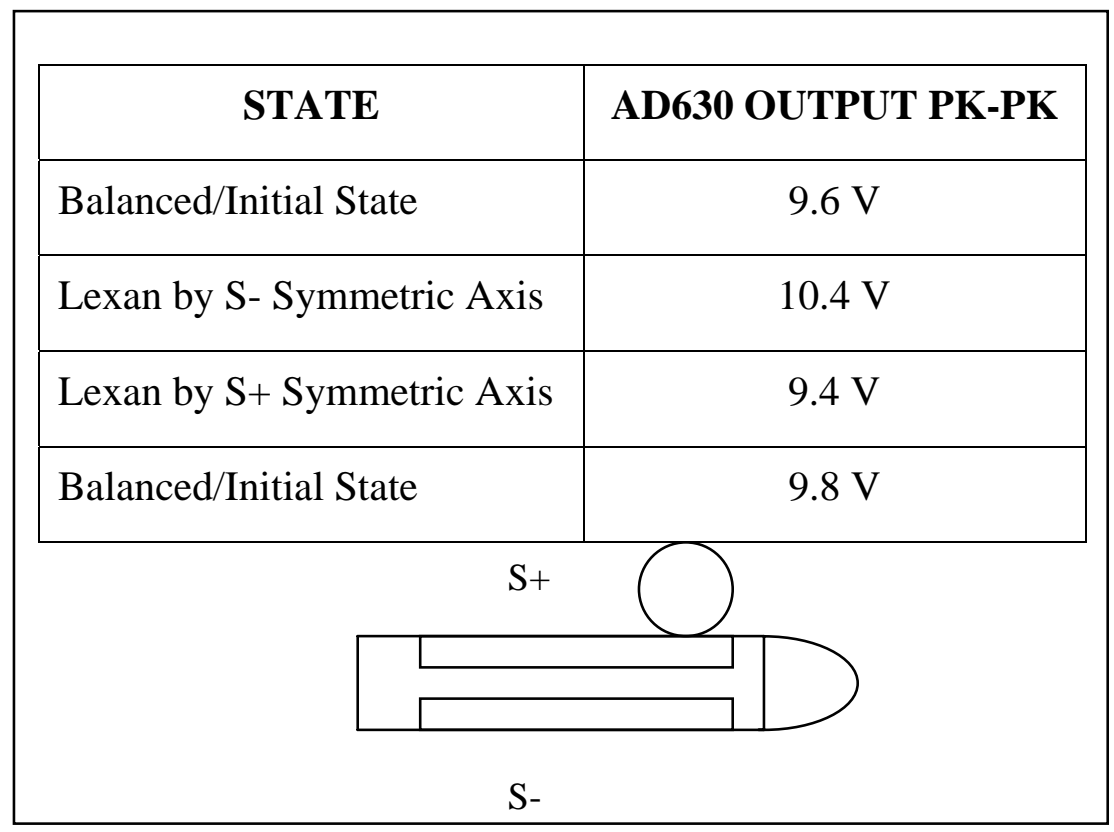

TABLE 1. DATA FROM LEXAN BENCHTOP TEST 
As seen by the results, the variance wasn't exactly the same for each element, but the relative change (above or below the initial state) occurred with each test. The return close to initial state was better than was seen by any previous configuration.

The oscilloscope screen captures for the data is shown below in Figure 17. The signal for the data is the pink/rectified signal, or the bottom trace. The top trace is the output of the function generator. The middle trace is the output directly from the S+ sense element before any amplification. An item to note is the pk-pk value of the S+ element did not change when the obstacle was placed by the S- element; only the AD 630 output changed. This verified that the copper tube in the middle of sense elements was doing a good job at shielding the elements from one another.

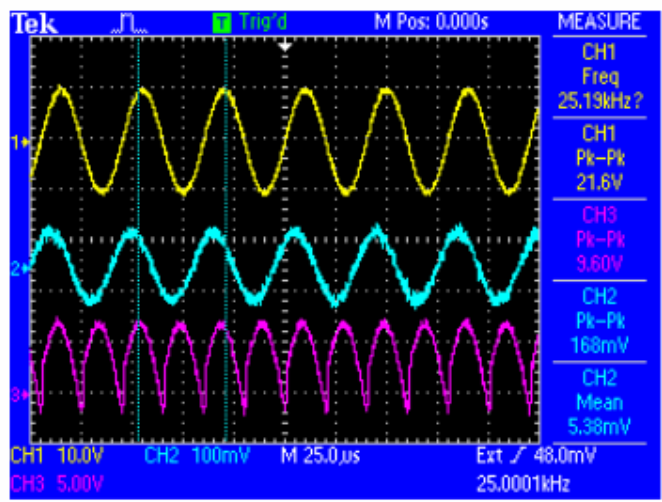

09/01/04 $25 \mathrm{kHz}, 10 \mathrm{~V}$ excite

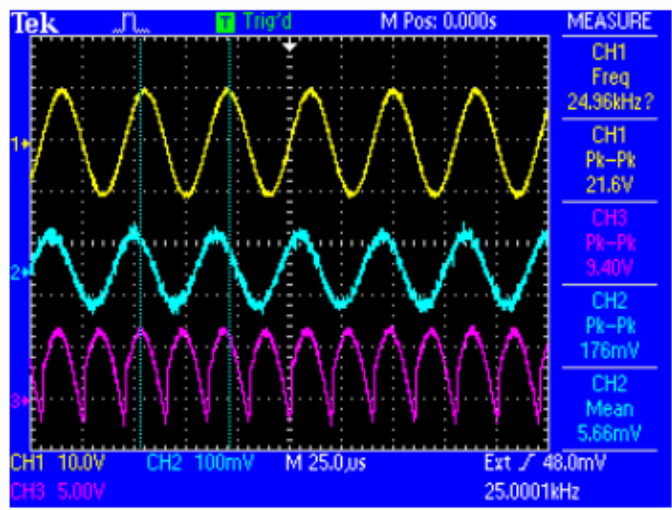

090104 plastic pipe on $\mathrm{S}+$ side

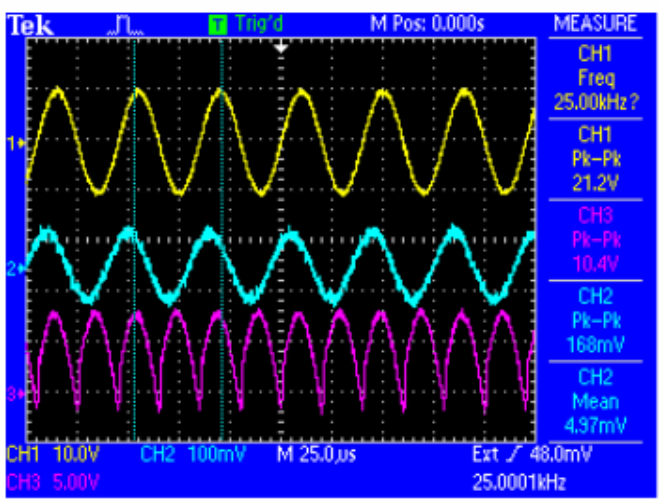

090104 - plastic pipe on S- side

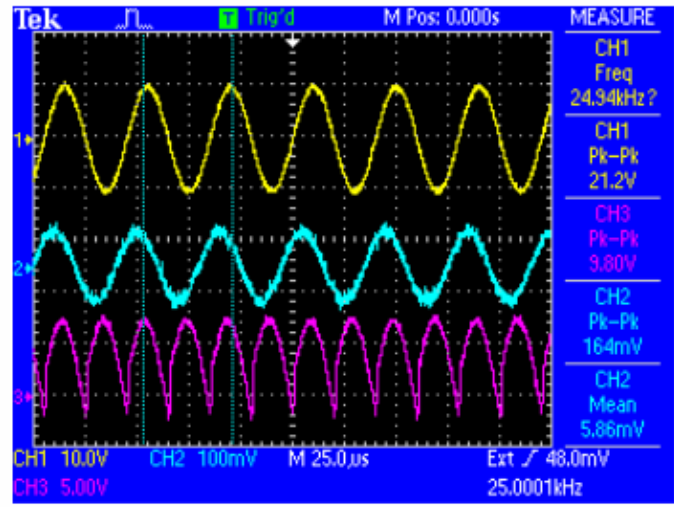

090104 - no pipe

Figure 17. Bench Top Tests With Lexan Obstacle 
One thing noticed during the bench top tests was that the phase of the excitation signal had to be changed each time the function generator was powered up if a balanced condition was desired. The device used for testing was a dual output arbitrary waveform function generator. One output was used as the excitation signal whose amplitude was altered throughout tests. The other output was the reference signal having the same frequency as the excitation signal, but whose amplitude didn't change. The reference signal was fed directly to the AD630 and compared with the signal from the sense elements after they went through the pre-amp and the differential amplifier.

The function generator has a master power button, and also individual power buttons to allow each output to be activated/deactivated separately. If the sensor was in a balanced state (no obstacle present) and the phase of the excitation signal altered to properly exhibit the balanced state (zero mean output from the AD630), the phase characteristics remained the same if just the individual output power buttons were toggled. However, if the master power button was switched off and on, and the same phase numbers manually entered, the output of the AD630 wasn't always in the same balanced state. Stated another way, although the sine and square outputs of the generator had the same frequency, the phase between the two was arbitrary each time the generator was powered up.

This issue is simply noted as contributing to past repeatability problems. Other than manually setting the balanced condition for each test, the issue wasn't addressed in further testing with the function generator since the function generator will not be present in the final prototype. The issue will be addressed when the signal generator components are placed in the pod, to insure there is some type of phase calibration before each HDD installation.

The next of the bench top tests were performed with the phase of the excitation signal adjusted to a balanced condition. This time, equally sized pipes (2.5” diameter) of copper and plastic were introduced as obstacles to verify the sensor behaved as expected. Since the background medium was air, it was expected that the copper pipe would cause more of an imbalance. If the background medium was soil, plastic was expected to provide a stronger response. In general, the sensor detects discontinuities in the electrical properties of its immediate environment. The copper pipe is a conductor in non-conductive air. The plastic pipe is an insulator and should be easy to detect when embedded in a homogeneous conductive (wet) soil. The dielectric properties of plastic are sufficiently different enough from air that it was detectable. The one challenge of detection might be with a background medium of dry soil. Polyethylene has a dielectric constant of about 2.25. Dry soil has a dielectric constant of 2.42.9.There is also a second boundary between the pipe and whatever fluid is contained within it. 
Air and methane both have dielectric constants close to 1; as contrasted to 2.25 for PE. Water can have a dielectric constant up to 80 depending on the ionic concentration. This second, internal boundary, may be detectable in some instances.

As expected initially, the copper pipe did cause more of an imbalance in air. The tests were performed with a 50kHz/20Vpp excitation signal, with the objects about 3” away from the sense elements. Care was taken to make sure the obstacles were placed in the same position on each side of the sensor. The data is shown in Table 2.

\begin{tabular}{|l|l|l|}
\hline & \multicolumn{1}{|c|}{ Copper Mean Out } & \multicolumn{1}{c|}{ Plastic Mean Out } \\
\hline Balanced/No Obstacle & $40.3 \mathrm{mV}$ & $35.1 \mathrm{mV}$ \\
\hline S- Imbalance & $6.53 \mathrm{~V}$ & $2.74 \mathrm{~V}$ \\
\hline S+ Imbalance & $-5.32 \mathrm{~V}$ & $2.82 \mathrm{~V}$ \\
\hline
\end{tabular}

TABLE 2. DATA FOR TESTS COMPARING COPPER AND PLASTIC IN AIR

Further tests showed that, in air, the sensor could pickup the obstacle up to 12” away. It was expected that this range should increase in soil. These previous statements were made prior to extensive soil testing. After talking with soil experts, it became apparent that soil characteristics are much more complicated than initially thought. It doesn't make these statements wrong, but it does suggest much more testing and modeling of the sensor configuration is required to get a better handling of the behavior that is expected in a more realistic soil condition.

The addition of the copper guard tube significantly improved results. Figure 18 shows a comparison of the signals when the copper tube is connected to ground compared to when it is not. The first picture in the figure shows the balanced state with the guard connected to ground. The second picture shows what happens when the guard is disconnected from ground. 


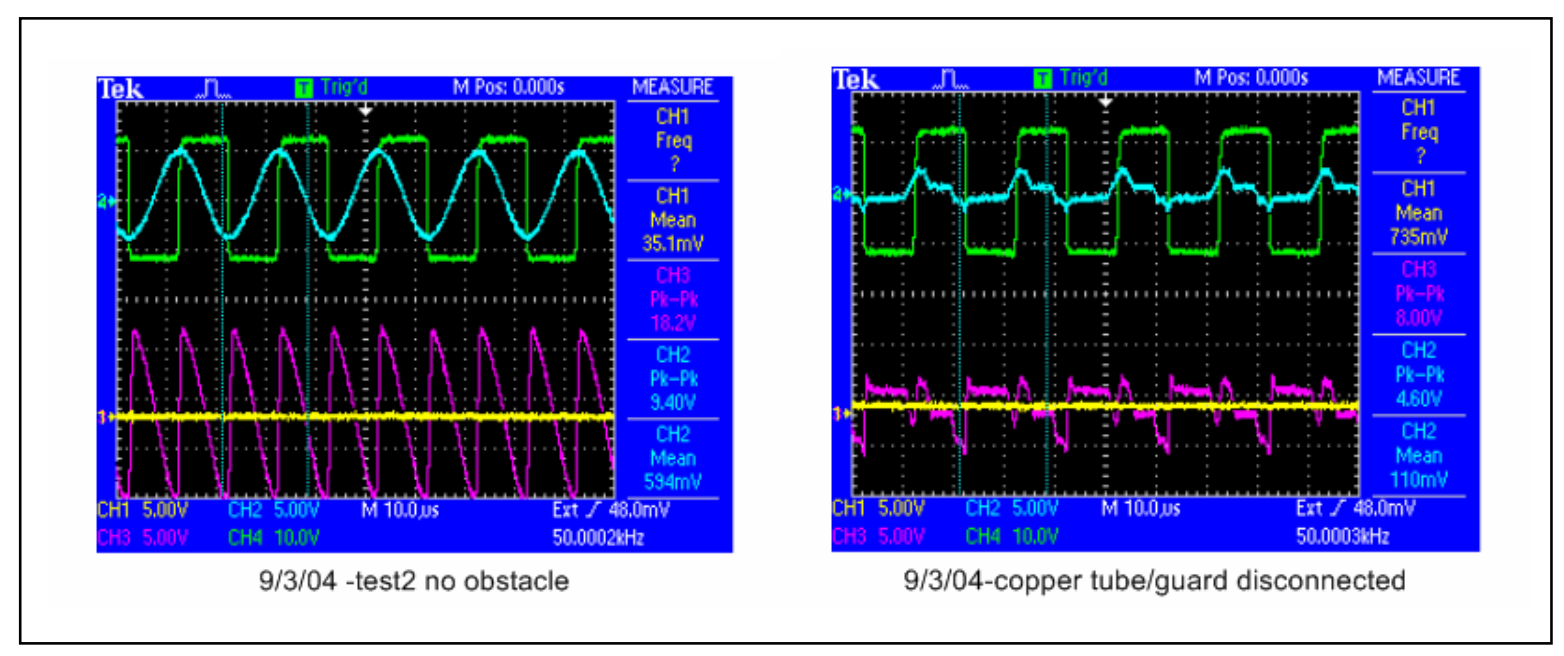

Figure 18. Comparison With/Without Copper Guard Tube Connected

Equations in the experimental section showed the values initially selected for the input and feedback resistors of the LF412 stage. Ideally, the output should show a gain of 10 in the frequency range of $100-300 \mathrm{kHz}$, but the gain did not properly correspond. The output of the LF412 was highest in the range of $10-60 \mathrm{kHz}$, with the peak output around $20-30 \mathrm{kHz}$.

At first it was thought that the plate-to-earth capacitance was different than calculated. To double check, the tests were repeated on a protoboard with a $23 \mathrm{pF}$ cap representing the plateto-earth capacitance and the function generator feeding directly to this capacitor. The figure below shows the output of the LF412 for two cases: Case 1 is with an input resistance of 120k and feedback resistance of $2.7 \mathrm{M}$. Case 2 is with the input resistance of $12 \mathrm{k}$ and feedback resistance of $120 \mathrm{k}$. 


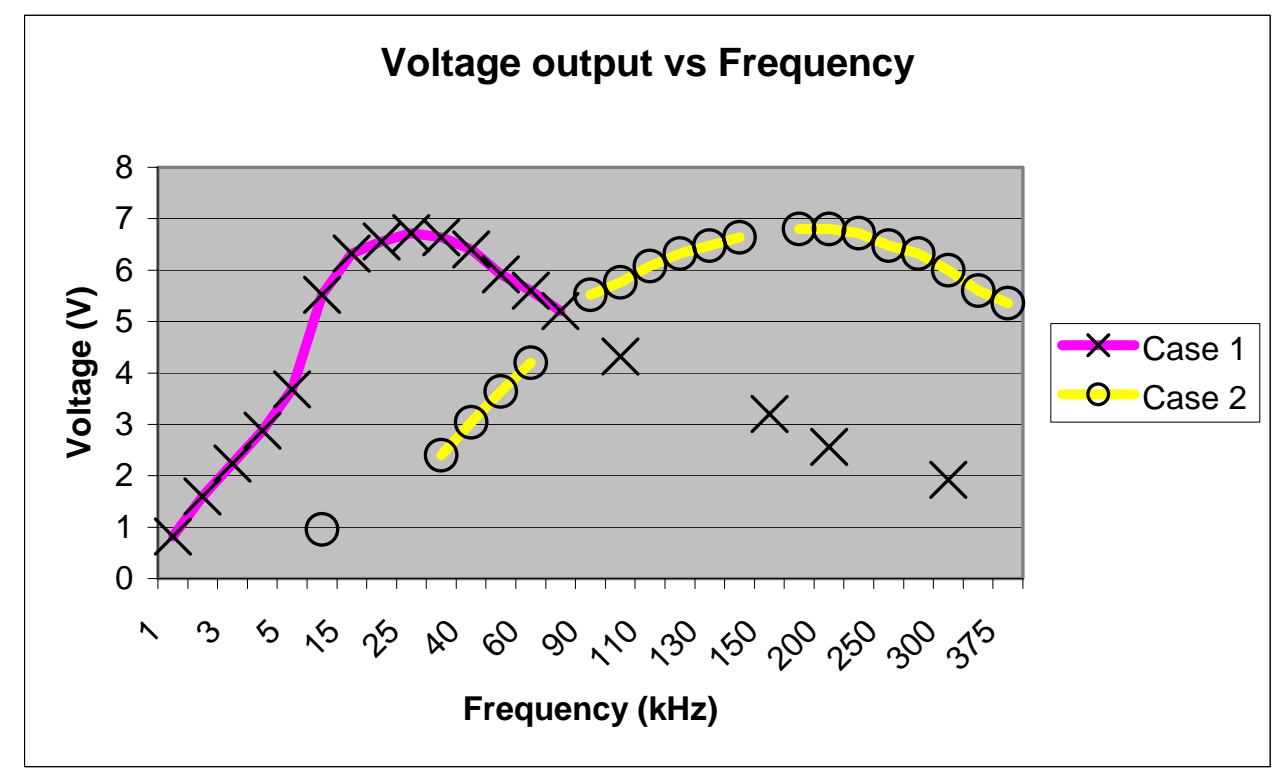

Figure 19. Graph of Output vs. Frequency Data from Table 3

Table 3 shows the data corresponding to the values in Figure 19. Looking at the output values of the LF412 for case 1, the best results occur in the $20-30 \mathrm{kHz}$ ranges, or $10-60 \mathrm{kHz}$ if you include values as low as $5.5 \mathrm{~V}$. Outside of this, the values start dropping substantially. This was not what was predicted by the ideal equations and amplifier specification. The bolded text is where the relatively flat responses of the gain occurred.

Since the frequency range was off by a factor of 10 , it was decided to try tests with the resistor values also dropped by a factor of 10 . This case is the third column of Table 3 using resistor values of $12 \mathrm{k}$ and $270 \mathrm{k}$.

In this case, the highest output occurred in the range of $150-225 \mathrm{kHz}$, or $110-300 \mathrm{kHz}$ if including 6.0V. The $23 \mathrm{pF}$ capacitor was taken out and the board hooked up to the sense elements. Very similar results were found; the maximum output occurred in the range of 90$300 \mathrm{kHz}$. The conclusion was that the higher resistance values caused the circuit to be overly sensitive to parasitic capacitance in the circuit board and cabling. The lower resistance values provided a flat gain characteristic in the frequency range of interest. 


\begin{tabular}{|c|c|}
\hline \begin{tabular}{l|l} 
Freq $(\mathrm{kHz})$ & Output Case 1 \\
\end{tabular} & Output Case 2 \\
\hline $1820 \mathrm{mV}$ & $\mathrm{N} / \mathrm{A}$ \\
\hline \begin{tabular}{l|l|l}
2 & $1.6 \mathrm{~V}$ \\
\end{tabular} & N/A \\
\hline $32.24 \mathrm{~V}$ & $\mathrm{~N} / \mathrm{A}$ \\
\hline $42.88 \mathrm{~V}$ & $\mathrm{~N} / \mathrm{A}$ \\
\hline $53.68 \mathrm{~V}$ & N/A \\
\hline $105.52 \mathrm{~V}$ & $960 \mathrm{mV}$ \\
\hline $156.32 \mathrm{~V}$ & N/A \\
\hline $206.56 \mathrm{~V}$ & N/A \\
\hline $256.72 \mathrm{~V}$ & $\mathrm{~N} / \mathrm{A}$ \\
\hline $306.64 \mathrm{~V}$ & $2.40 \mathrm{~V}$ \\
\hline $406.40 \mathrm{~V}$ & $3.04 \mathrm{~V}$ \\
\hline \begin{tabular}{l|l}
$50.92 \mathrm{~V}$ \\
\end{tabular} & $3.64 \mathrm{~V}$ \\
\hline $\begin{array}{lll}60.60 \mathrm{~V} \\
\end{array}$ & $4.20 \mathrm{~V}$ \\
\hline $\begin{array}{lll}70.20 \mathrm{~V} \\
\end{array}$ & N/A \\
\hline 90 N/A & $5.52 \mathrm{~V}$ \\
\hline \begin{tabular}{l|l}
100 & $4.32 \mathrm{~V}$ \\
\end{tabular} & $5.76 \mathrm{~V}$ \\
\hline \begin{tabular}{l|l}
110 & N/A \\
\end{tabular} & $6.08 \mathrm{~V}$ \\
\hline $120 \mathrm{~N} / \mathrm{A}$ & $6.32 \mathrm{~V}$ \\
\hline $130 \mathrm{~N} / \mathrm{A}$ & $6.48 \mathrm{~V}$ \\
\hline $140 / \mathrm{N} / \mathrm{A}$ & $6.64 \mathrm{~V}$ \\
\hline $1503.20 \mathrm{~V}$ & N/A \\
\hline 175 N/A & $6.80 \mathrm{~V}$ \\
\hline $2002.56 \mathrm{~V}$ & $6.80 \mathrm{~V}$ \\
\hline $225 / \mathrm{N} / \mathrm{A}$ & $6.72 \mathrm{~V}$ \\
\hline $\begin{array}{ll}250 & N / A \\
\end{array}$ & $6.48 \mathrm{~V}$ \\
\hline 275 N/A & $6.32 \mathrm{~V}$ \\
\hline \begin{tabular}{l|l|l|}
300 & $1.92 \mathrm{~V}$ \\
\end{tabular} & $6.00 \mathrm{~V}$ \\
\hline \begin{tabular}{l|l}
350 & N/A \\
\end{tabular} & $5.60 \mathrm{~V}$ \\
\hline 375 N/A & $5.36 \mathrm{~V}$ \\
\hline
\end{tabular}

TABLE 3. GAIN CHARACTERISTICS. $R_{\mathrm{IN}}=120 \mathrm{~K}, R_{\mathrm{F}}=2.7 \mathrm{M}$ (CASE 1) $R_{\mathrm{IN}}=12 \mathrm{~K}, R_{\mathrm{F}}=120 \mathrm{~K}$ (CASE 2)

At first it was thought the optimal resistors were found. But when looking at the rest of the circuit there appeared to be a slope overload issue with the AD621 (differential amp stage after the LF412). At $200 \mathrm{kHz}$ the waveform started to triangulate, rather than tracking the sine wave fed to the input. Also the phase and bias levels of the AD621 output signal were affected with a change in amplitude of the excitation signal. All of these were indicators that the signal was changing more rapidly than the amplifier could track. This was at odds with the published specification for the AD621.

For reference look at the screen captures shown in Figure 20. The frequency was kept at $200 \mathrm{kHz}$, but the excitation signal amplitude was increased. For the first three screen-captures, the square wave trace is the output of the function generator used as the reference signal, which 
remained unchanged. The smaller trace among the top two is the output of the 621. The bottom trace is the output of the function generator used for the excitation signal.

For the next three captures, the middle trace is the output of the 621. The top two traces are the excite signal and the output of the LF412 for one of the elements. The bottom trace is the output the AD630. The only important trace to compare in all signals is the output trace of the AD621.

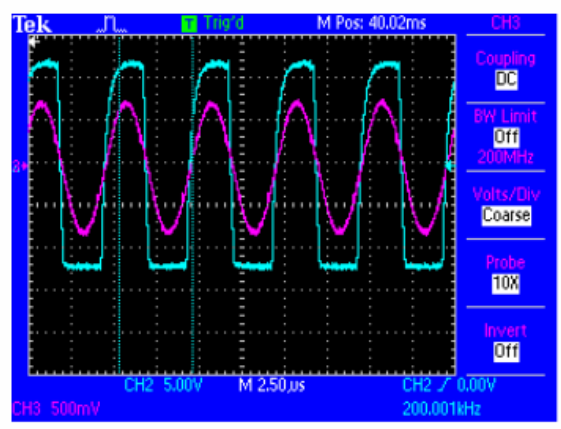

output621: $2.12 \mathrm{Vpp}$ excite

$200 \mathrm{kHz}$

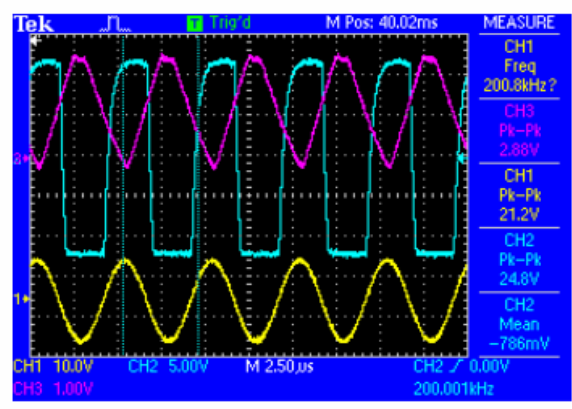

621out:10V gen out; $21.2 \mathrm{Vpp}$ excite

$200 \mathrm{kHz}$

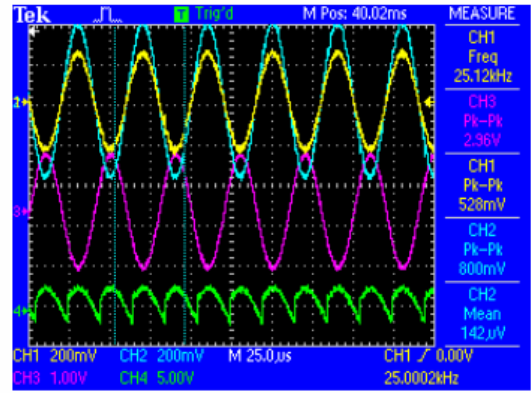

$120 \mathrm{~K} / 2.7 \mathrm{M}, 25 \mathrm{kHz}$ excite, stil $2.8 \mathrm{~V}$ gen

$25 \mathrm{kHz}$

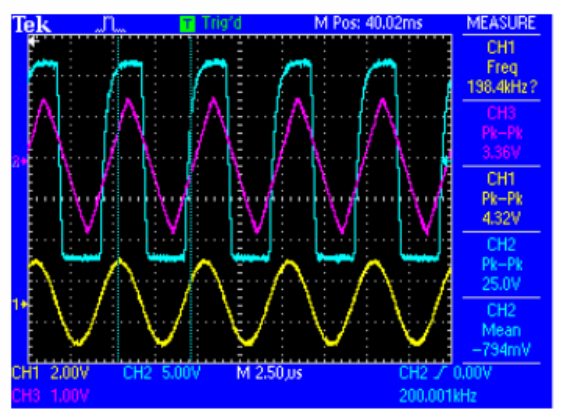

621out:4.32 Vpp excite

$200 \mathrm{kHz}$

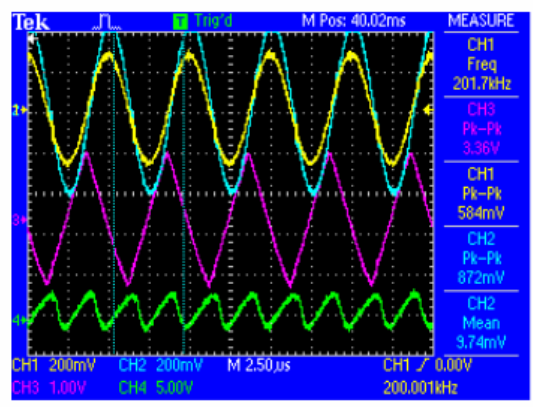

$12 / 270$, but with gen at $2.8 \mathrm{~V}$

$200 \mathrm{kHz}$

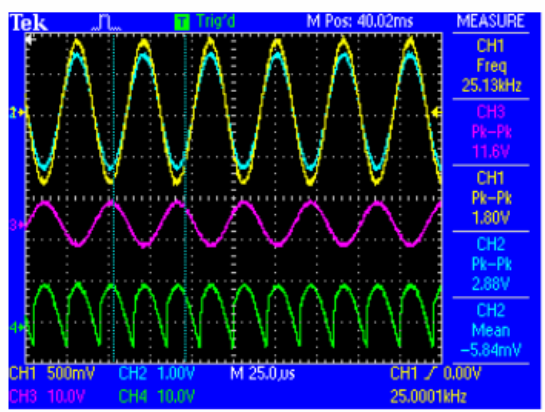

$10 \mathrm{~V}$ gen $(\max )$

$25 \mathrm{kHz}$

Figure 20. Distortion at $200 \mathrm{kHz}$ vs. $25 \mathrm{kHz}$ 
It's difficult to see the values in the captures, but the waveform for $200 \mathrm{kHz}$ started to triangulate at $3.36 \mathrm{~V}$ pk-pk. When comparing with a frequency of $25 \mathrm{kHz}$, but with resistors of $120 \mathrm{k}$ and $2.7 \mathrm{M}$, the sloping effect did not come into play. With a frequency of $25 \mathrm{kHz}$, the pk-pk could get up to $11.6 \mathrm{~V}$ and still not triangulate. Based on these observations the in-soil testing was performed at $25 \mathrm{kHz}$.

The sensor was then tested in the loam test bed. In the first test with the permanent pipe as the obstacle (the sensor placed just above and to the side of the pipe), the symmetric axis was parallel to the pipe to achieve balance. The phase of the excitation signal was adjusted so the mean filtered output of the AD630 was $-212 \mathrm{mV}$. With the S+ element facing the pipe, the mean output jumped to $-4.81 \mathrm{~V}$. With the $\mathrm{S}$ - element towards the pipe, the mean output changed to $4.94 \mathrm{~V}$.

Initially these results looked very good, but when the sensor was rotated just slightly either way, the S- output could quickly jump negative. This was either because the field of view for the sense elements was too small or there was a contact issue with the soil, especially where the tip interacted with the ground. The latter is more likely true since the readings could also be affected by pressing the sensor against the soil wall. Again, FE Modeling might help to determine this.

One of the theories of the contact issue is in the process of rotating the sensor, the drill tip digs out a slight air pocket in the soil. The sensor is designed to use the shape of the drill tip to its advantage, especially when comparing the symmetric and asymmetric axes. When an air pocket is created around the tip, the electrical contact with the soil is compromised. This is an artifact of the way the experiment was performed; in a real HDD the drill rotates and moves forward simultaneously. The forward motion should maintain contact between the soil and drill tip.

To test the contact issue, water was poured into the hole around the sensor. Since the loam soil has a slight mixture of clay, it generally filters water a little slower than sand so water remains in the hole longer.

The water didn't help with keeping the readings steady, although there was a visible change seen in the signal if the sensor was rocked slightly back and forth while the water was settling (i.e. where the water level was settling around the drill stem). This suggests that there must indeed be a contact issue. 
The next test was with a smaller section of 4” PE pipe. Whereas the permanent pipe tests were done with the sensor slightly above and to the side of the pipe (similar to the orientation in an HDD installation), the tests with the smaller pipe were done with the pipe at the same level as the sense elements. This is a similar orientation of the obstacle when the bench top tests were performed. This time, though, the sensor is being rotated to determine the field of view of the sense elements.

The pipe was placed about 2.5-3' deep into the loam soil with the sensor 4" away from the pipe. As the sensor was rotated, the sensor was lifted up slightly and placed back down before the reading to optimize the tip to soil contact and limit any air pocket created. The orientation of the sensor is shown in Figure 21 with data shown in Table 4.

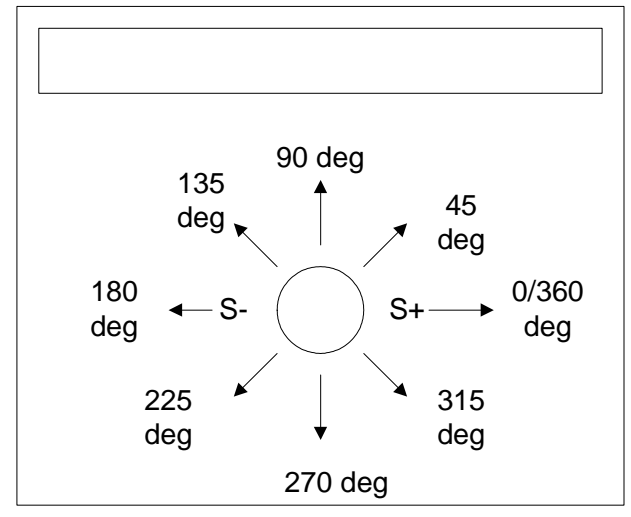

Figure 21. Orientation Of Rotation Test

\begin{tabular}{|l|l|}
\hline Degrees & Output \\
\hline 0 & $874 \mathrm{mV}$ \\
\hline 45 & $-4.68 \mathrm{~V}$ \\
\hline 90 (S+ towards pipe) & $-4.28 \mathrm{~V}$ \\
\hline 135 & $-4.40 \mathrm{~V}$ \\
\hline 180 & $325 \mathrm{VV}$ \\
\hline 225 & $4.34 \mathrm{~V}$ \\
\hline $270($ S- towards pipe) & $5.06 \mathrm{~V}$ \\
\hline 315 & $2.99 \mathrm{~V}$ \\
\hline 360 & $-632 \mathrm{mV}$ \\
\hline
\end{tabular}
TABLE 4. RESULTS FROM ROTATION TEST

From the data it can be seen that the sensor had about a quadrant per sense element field of view. However, at times during the test, slight movement of the sensor did cause the values to 
jump similar to what was seen with the permanent pipe tests. When this occurred, the sensor was lifted and reset, giving a good reading.

Even though there was still an apparent contact issue with the newest hybrid design of the sensor, it was much better than other configurations. In addition, the strength of the signal seen by the sense elements was more stable, with no bias drifts.

The time allotted in the original scope of work plus a no-cost time extension expired, so no other research work was done on this project. Several other tasks were supposed to be performed, including testing the sensor in a variety of soils, incorporating a tilt sensor to measure inclination and conducting a series of in-ground tests. Aside from the preliminary tests in loam soil, plus earlier tests in sand and electrolyte solutions, no further tests to examine soils properties or perform in-ground tests with HDD could be performed in this phase. It became apparent that the evaluation of bridge sensors combined with soil properties was much more complicated than originally thought.

Even though the DOE obligation has ended, there is promise for the project through other sponsors. The research portion of the project was co-funded by FERC. After the end of work for DOE Sept 30, 2004, the project was presented at the IGRC 2004 conference in Vancouver in November 2004. Despite the project admittedly falling short of the milestone schedules, it was well received by the audience. This is even compared to a GPR based look-ahead device that was presented in the same session.

One thing that became very apparent after presenting the paper and talking with various manufacturers of soil impedance measurement devices is the need to get a better handling on the behavior of field lines given the geometries, materials, and excitation frequencies of the sensor configuration. One such manufacturer that proved very helpful was TransTech Systems (http://www.transtechsys.com). One suggestion was to model the configuration in a FE modeling program like FEMLAB (http://www.comsol.com). Unfortunately the power of such a program to predict behaviors in soil properties wasn't realized until late in the project. If FEMLAB was used earlier in the project, more of the tasks may have been performed.

The FERC portion of the project is ending December 31, 2004 but the project may continue through funding by the American Water Works Association (AWWARF). AWWARF originally allocated funding just for commercialization, but after presenting the results from the IGRC presentation and talks with other researchers, they are open to potentially allowing a portion of the funding to be used for additional basic research. 


\section{CONCLUSIONS}

Below is a concise listing of the different versions of the sensor throughout the project as well as what was learned at each point. A more detailed commentary on the overall lessons learned follows the list.

1. First version based on initial technical approach (Figure 4).

a. Pros: This version showed some change in the signal when an obstacle was placed near one of the sense elements.

b. Cons: The sensitivity was much lower than expected. It was also realized that the configuration would likely have further sensitivity problems when attached to a long length of drill stems.

2. Possible solution (Figure 11): The next version was based on resistive rather than capacitive tomography. The signal was injected at the tool blade tip and collected by the drill pipe. The sense elements were in direct contact with the soil (as protrusions on the surface of the pod rather than placed within the pod inside the lexan). Steel pipe was added to represent the drill stem. Also during this phase, testing was done in an electrolyte solution in the hopes of having a more uniform sensing medium.

a. Pros: The drive configuration was an improvement in that it forced the excitation current into a definite path from the leading drill tip to the trailing drill stem. The original configuration had an ambiguous current path into the sensor from either the tip or stem.

b. Cons: There were still sensitivity issues. The sense elements were initially made of stainless steel. Since the tool blade tip was made of carbon steel, a potential was created which affected the readings. There was also insufficient shielding of the sense elements from the drive signal emitting internally in the pod. Also have to consider that sense elements protruding from the device may wear under field conditions.

3. Possible Solution (Figure 12): Change sense element screws to steel, add shielding around threaded rod so sense elements have more sensitivity to excitation signal coming through the soil

a. Pros: There wasn't as large of a potential created by the tool blade-sense element interaction. 
b. Cons: Still had contact/sensitivity issues

4. Possible Solution (Figure 13): Increase sense element size by added carbon steel shim stock to set screws

a. Pros: Not many

b. Cons: Still had contact issues; readings significantly different depending on whether or not the sense element was touching the soil wall.

5. Possible solution: Hybrid using best of versions so far; resistive signal injection, with no air gap between sense elements and skin

a. Pros: Slightly better results

b. Cons: Still had balance issues

6. Possible Solution (Figure 14): Increase lexan portion to include first stage amplifier as close as possible to sense elements; also insert copper tube to limit element-to-element cross talk

a. Pros: Best results thus far. Able to achieve balance, differentiate between copper and plastic targets in background medium of air. Could also detect imbalance caused by plastic target in soil media. A quadrant per sense element viewing area was also observed as the sensor was rotated.

b. Cons: Still come repeatability issues, especially in soil. Still have some contact issues, although not nearly as bad as previous prototypes

7. Possible Solution: End of Project, so no more work could be done. If time allowed, it would have been suggested to perform modeling on sensor before next prototype made.

Admittedly the project fell short of successful completion of all the tasks, more due to time available and lack of foresight rather than cost or feasibility of the technology. The greatest lesson learned is the characteristics of soils and their effects on field lines should have been examined much earlier in the project, even before the first prototype was built. The other lesson learned is what may have worked in related projects won't necessarily work so easily when incorporated in a HDD environment. 
GTI had success in a previous project with low frequency data transmission of its wireless tow tension monitor used during the pullback stage of HDD installations. Also, there has been success with its current capacitive tomography project using low frequency to detect plastic pipe from above ground. It was assumed these two technologies would yield to early successful results when incorporated with an obstacle detection sensor underground. This was not the case. Even though the tow tension monitor can transmit data far distances and dealt with some of the mechanical constraints associated with HDD component design, it didn't account for soil effects on sensing issues. The capacitive tomography project did examine the sensing issues a bit more, but since it is an above ground sensor and not limited to the physical constraints of an HDD drill head, it has the luxury of increasing the number of sensor array elements for better resolution as well as using more sophisticated data acquisition components that require more power to run. Combining the two wasn't so straightforward.

Regardless of these errors early on, the technology is certainly still feasible. Changes to the mechanical and sensing configurations along the course of the project did show progress. The sensor went from being very susceptible to noise and having poor sensitivity to obstacles early on, to having very good noise rejection and having the ability to differentiate, repeatedly, between metal and plastic obstacles in air. It had the ability to sense up to 12 ” in air and a quadrant per sense element viewing area in soil. However, the time spent to get to that point was far too great and there were still repeatability issues when placed underground.

Not until the end of the project was it realized that an electromagnetic modeling program would shed some light on the potential sensing issues of a look-ahead sensor incorporated in a drill head. This became most apparent after the project was presented at the International Gas Research Conference in November 2004. Several attendees acknowledged it was a very complicated approach to undertake given the low frequency, lack of resolution and physical constraints of an HDD head; yet they agreed it was a very worthwhile and feasible technology to pursue. Even other research organizations doing similar technologies using GPR admitted the benefits that a low frequency system would have over their own.

TransTech, a commercial manufacturer at the conference, relayed their experience with their products that deal with evaluating soil properties. They had similar assumptions as we did early on in the development of some their products that didn't yield successful results when tested in the field. Even when they modeled the issues in FEMLAB, they didn't believe the changes would work since the software showed results far different from their conventional theory. Yet when they made the changes, the product worked. 
The GTI approach is further complicated because of the mechanical constraints of an HDD drill head. A drill head has to be very robust to work in a hostile environment, which usually means hard metal or other material needs to be used throughout, especially at points that are most load bearing in the system. But for electromagnetic field propagation, especially involving soils, even the slightest bit of metal can wreak havoc if not guarded properly. Furthermore, even what's thought as a homogeneous soil condition can have strange effects on field lines with the slightest change in moisture content. None of these issues render the technology unfeasible, they just provide further support that a modeling program applied early on could have exposed many of the sensing issues before the first prototype was made.

Regarding any changes to the work statement that might have made the project more successful, the "evaluate sensor concept" task still would have been performed first, but extensive modeling would have been performed before preliminary prototypes were created and tested in the lab. There was also an "evaluate soil properties" built in to the statement of work. However, part of this was to examine the performance of the prototype in different soil mediums. This portion should have also been modeled in FEMLAB before the first prototype was even built. This in no way undermines the need to build and test a prototype; models must always be verified with experimental data.

Also, consulting research experts in the field of electromagnetic sensing of soil properties should have been performed more extensively early on to shed light on potential issues overlooked in the modeling stages. GTI personnel regularly consult with co-workers of other disciplines to make sure they are not missing something. That is certainly one of the strengths of the company: projects of man focus areas are researched, so there is a wealth of knowledge available. This was certainly done to a degree in this case, but the project would have benefited from even more consultation with more experienced researchers at other facilities that do this sort of work on a regular basis. Part of the reason for not doing this is simply the investigators didn't have some of the contacts that were developed by working and presenting on this project. However, this wouldn’t have solved all the problems. Even a company like TransTech that has been dealing with the focus area of soil properties and FEMLAB modeling for several years acknowledges they still learn new effects of soil properties on field lines with every model. 


\section{Work Performed}

\section{$\underline{\text { Task 1: Program Management }}$}

Quarterly reports were prepared and submitted throughout the duration of the project. This report will serve as the final technical report.

The only other new change that should be noted is for task 1b, state of the art assessment. At IGRC 2004, GTI learned of a Look-Ahead Technology being developed in Japan that uses GPR on the drill head. The device does better at imaging, but range is only about $30 \mathrm{~cm}$. Mr. Takahuru Nakauchi of The Japan Gas Association/Osaka Gas Co is performing the work along with other colleagues at Osaka Gas, Tokyo Institute of Technology, and the University of Tokyo.

\section{Task 2: Evaluate Sensor Concept}

Sub task 2.1, “Evaluate Impedance Bridge Based Sensors” took far longer than originally anticipated, and the task was never fuller completed. Tests with the newest hybrid sensor were performed on the bench top and the in the large indoor soil test bed. Tests on the bench showed a range up to 12”, with copper causing more of an imbalance (as expected). Tests in soil were successful with a range of 2', but the maximum was not tested. The field of view was approximately one quadrant per sense element.

Sub task 2.2, "Evaluate Soil Properties” was only partially carried out. The sensor was tests in an electrolyte solution, in sand, and in a loam soil. However, only relative changes of data caused by a few different obstacles were performed. A proper evaluation of soil properties and presentation of data would require more work.

Because the other two tasks weren't complete, sub task 2.3 “Design of Task 3 Demonstration” could not be properly performed. Only preliminary tests in the loam soil test bed involved the rotation of the sensor, but a proper demonstration would involve testing the device in a live in-ground HDD test. 


\section{Task 3: Demonstrate Obstacle Detection in Ground}

Initial tests were performed in the loam test bed, but only with the sensor vertically placed in the soils and rotated to sense a permanent obstacle. There was not time to get all the components into the pod and test the device with a horizontal directional drill.

\section{$\underline{\text { Technical Problems Encountered }}$}

There was still a slight contact issue with the hybrid configuration, but greatly improved over previous designs. The contact between the drill tip and the soil can degrade as the drill is rotated in place. In real operation the drill would also be moving forward while rotating. It is felt that the tip contact issue may be an experimental artifact. This could not be verified unless the field lines were properly modeled to better approximate the behavior of the sensor in soil.

\section{$\underline{\text { Project Management Problems Encountered }}$}

No project management problems were encountered.

\section{Action Requested of DOE NETL Project Manager}

A final quarterly report was submitted Nov $1^{\text {st }}$ of 2004 . This report serves as the final report for DOE 
WORK PLAN

Work Planned For The Future

No other work will be performed under this DOE contract. As mentioned, though, AWWARF is considering applying some of the funding originally intended for commercialization and using it for further development. To prevent conflict of interest with the scopes of work with this project, a new proposal with newly defined tasks will be submitted to AWWARF. 


\section{REFERENCES}

In a patent entitled “ Driven Shielding Capacitive Proximity Sensor”, patent number 5,166,679, dated November 24, 1992, inventors John M. Vranish and Robert L. McConnell have presented an invention for a capacitive proximity sensor that will detect the intrusion of a foreign object into the working space of an electrically grounded robotic arm. The capacitive proximitysensing element is backed by a reflector that is driven by an electrical signal of the same amplitude and phase as that signal which is detected by the sensor. It is claimed that by driving the reflector plate with the same signal that is on the sense element significant increases in the sensor's range and sensitivity are accomplished.

In a patent entitled “Steering Capaciflector Sensor”, patent number 5,363,051, dated November 8, 1994, inventors Del T. Jenstrom and Robert L. McConnell, present an invention that will allow for the steering of the electric field lines produced by a capacitive type proximity sensor. The inventors assert the claim that by steering or focusing the electric field will allow an increased ability to discriminate and determine the range of an object in the area of observation over that of previous capacitive sensors. Differential voltages applied to shielding plates spatially arranged around the sensor plate accomplish steering of the electric field lines.

In a patent entitled "Buried Pipe Locator Utilizing A Change In Ground Capacitance”, patent number 5,617,031 dated April 1, 1997 inventor John E. B. Tuttle has invented a portable buried pipe detection device that utilizes changes in the electrical properties of the soils surrounding underground pipes. The detection method consists of the injection of a low frequency sinusoidal wave into the ground via an array of injector/sensor plates. Subsequent modification of the injected signal by variations in ground impedance brought about by the existence of buried piping structures will result. The modified signals will be detected by the spatially separated sensor elements located on the device. The injector/sensor elements are constructed in such a manner as to comprise a capacitive bridge circuit when viewed in conjunction with the ground. As the detection array is moved along the ground any occurrence of underground piping structures will imbalance the capacitive bridge and give rise to a detectable electrical signal.

The website entitled “Underground Radio by Le Magicien” was used to help design and explain the new sensor configuration. The website is located at http://www.geocities.com/lemagicien_2000/elecpage/ugr/undr.html. 


\section{LIST OF ACRONYMS ABBREVIATIONS}

AWWARF - American Water Works Association Research Foundation

CT - Capacitive Tomography

COR - Contracting Officer's Technical Representative

DOE - Department of Energy

FERC - Federal Energy Regulatory Commission

GPR - Ground Penetrating Radar

GRI - Gas Research Institute

GTI - Gas Technology Institute

IGT - Institute of Gas Technology

IRNG -Infrastructure Reliability of Natural Gas 


\section{APPENDIX A \\ Differential Soil Impedance Obstacle Detection \\ Detailed Work Plan}

\section{A. OBJECTIVES}

The objective of this project is to design, fabricate, and test a prototype sensor system for detecting obstacles in front of or around the head of a horizontal directional drilling (HDD) rig. The sensor system shall be sensitive to metallic, plastic, or ceramic obstacles embedded in the soil. The detection live power lines with the same sensor will also be investigated.

\section{B. SCOPE OF WORK}

In order to reach the goal of designing, fabricating, and testing, a viable prototype of an obstacle detection system for guided directional drilling, GTI shall perform the following tasks.

1. Program Management

2. Evaluate Sensor Concepts

3. Demonstrate Obstacle Detection in Ground

The completion of these Tasks in an orderly fashion will result in the fabrication and testing of a sensor that can be mounted on the drilling head of a horizontal directional drill. The sensor will be tested with a mixture of target obstacles in soil. This testing will be performed using a sensor probe driven vertically into the soil rather than horizontally bored in the interest of saving time and costs. 


\section{DELIVERABLES AND SCHEDULE}

1.0 Program Management

1a Detailed Work Plan - 6/02

1b State of the Art Assessment - 7/02

1c Quarterly Technical and Financial Reports - 8/02, 11/02, 2/03, 5/03

1d Final Technical Report - 8/03, 10/03

1e Topical Reports and presentations as required

2.0 Evaluate Sensor Concepts

2a Evaluation of Impedance Bridge Sensors -11/02

2b Evaluation of Soil Properties - 2/03

2c Detailed Plan for In Ground Tests - 4/03

3.0 Demonstrate Obstacle Detection in Ground

3a Test Passive Sensing of Live Power Mains - 5/03

3b Test Active Sensing of Obstacles - 6/03

3c Demonstrate Sensor with Multiple Obstacles - 7/03 


\section{TASK WORK DETAILS}

\subsection{Program Management}

This task will subsume all the necessary reporting, meeting, presentation, and demonstration requirements for DOE. The FERC provided cofunding will cover any additional program management requirements incurred by the gas industry sponsors.

\section{$\underline{1.1 \text { Research Management Plan }}$}

GTI shall develop a work breakdown structure and supporting narrative that concisely addresses the overall project as set forth in the agreement. GTI shall provide a concise summary of the technical objectives and technical approach for each Task and, where appropriate, for each subtask. GTI shall provide detailed schedules and planned expenditures for each Task including any necessary charts or tables, and all major milestones and decision points. This statement of project objectives shall form the basis for the deliverable Research Management Plan

\section{$\underline{1.2 \text { Technology Assessment }}$}

GTI shall prepare and submit a report describing the current state-of-the-art of the technology being developed. The report should describe existing technologies and positive and negative aspects of using this technology. The report shall not exceed five typewritten pages in length. The report is not to contain any proprietary or confidential data as the report will be posted on the NETL website for public viewing. The report is to be submitted within 60 days of award. The DOE Contracting Officer's Technical Representative (COR) shall have 20 calendar days from receipt of report to review and provide comments to the contractor. Within 15 calendar days after receipt of DOE's comments, the contractor shall submit a final Report to the DOE COR for review and approval. 


\section{0 Evaluate Sensor Concept}

In this task GTI will do a more detailed evaluation of specific technologies relating to obstacle detection. Some of these technologies may be identified in the state of the art evaluation. Bench experiments will be carried out in this task preparatory to performing tests in soil.

\subsection{Evaluate impedance bridge based sensors}

GTI shall survey existing methods of remote obstacle detection with a focus on those methods employing impedance bridge based sensors. Capacitively coupled impedance bridges have been evaluated for the location of sub-surface plastic objects such as plastic pipes and landmines. There is also a large body of work dealing with capacitive sensors for soil moisture measurement.

Simple experiments shall also be carried out in this task. A small-scale model consisting of a steel rod with an angled tip and an electrode array shall be constructed. This shall be tested in an electrolyte tank with submerged samples of various obstacle materials. Custom electronics are not necessary for these experiments. They shall be carried out using laboratory instrumentation.

\subsection{Evaluate Soil Properties}

Given the critical interaction between the soil and the sensing method, current data on soil properties shall be examined. The conductivity and dielectric properties of typical obstacles shall also be examined at this time. Soil survey data shall be obtained to estimate the distribution of soil types over North America. Part of this sub-task is to identify any "problem” soil types and extents. Any deficiencies in soil dielectric and conductivity data shall be identified at this time. Using the previously constructed probe and laboratory instruments, tests shall be carried out on single obstacles in representative soils.

\subsection{Design of Task 3 Demonstration}

Once the sensor and soil data are available, design of experiments shall be carried out. Tests for the detection of electric power mains in both the energized and off states by passive methods shall be designed. Tests for detecting and ranging inclusions in the soil by change of impedance shall be designed. Examples of obstacles with impedance lower than the soil are cast iron or metal pipes and metallic debris. Examples of obstacles with impedance higher than the soil are plastic pipes, clay tiles, and masonry rubble. 


\subsection{Demonstrate Obstacle Detection in Ground}

Using the results of Task 2, GTI will demonstrate the detection of obstacles using differential impedance measurements in soil.

\subsection{Passive Sensing Tests}

In passive sensing tests the sensor probe will be used to detect the electromagnetic radiation signature emitting by live power lines. The probe will not emit signals in the frequency range characteristic of power lines. Electric mains may be buried directly in soil or buried in metal, concrete, or plastic conduits in the soil. Electric mains may be carrying three-phase or single-phase power at various voltage and current levels. These power lines shall have known voltages, currents, and phasing. In order to test the passive EM sensing mode of the array in soil, the test probe array shall be inserted vertically into the ground in the proximity of AC mains. Current and voltage monitors on the power mains will provide reference data for the evaluations of the array's sensitivity to this category of sources

\section{$\underline{3.2 \text { Active Sensing Tests }}$}

In active sensing tests the sensor probe will be injecting an electrical signal of known characteristics into the soil. GTI shall develop a simplified field test site. Input shall be solicited from industry advisors during the construction of this facility to insure that relevant features are not overlooked. The number of representative soil types shall be determined. Appropriate numbers and sizes of obstacles shall be buried. Test sites that provide interference between obstacle types shall be included.

\subsection{Perform Obstacle Detection Tests}

After the simplified field environment has been completed, tests to determine the range, accuracy, and resolution of the sensor array shall be carried out. The effects of soil type, obstacle type, and obstacle size on array performance shall be observed. These experiments shall be performed with vertically driven probe arrays in the interests of keeping costs within bounds. These probes shall be driven incrementally closer to buried obstacles while simultaneously rotating the probe. A simple user interface and display shall be constructed to facilitate these tests. 


\section{APPENDIX B}

Presentation for International Gas Research Conference, Vancouver, BC, Canada; November 2, 2004. 


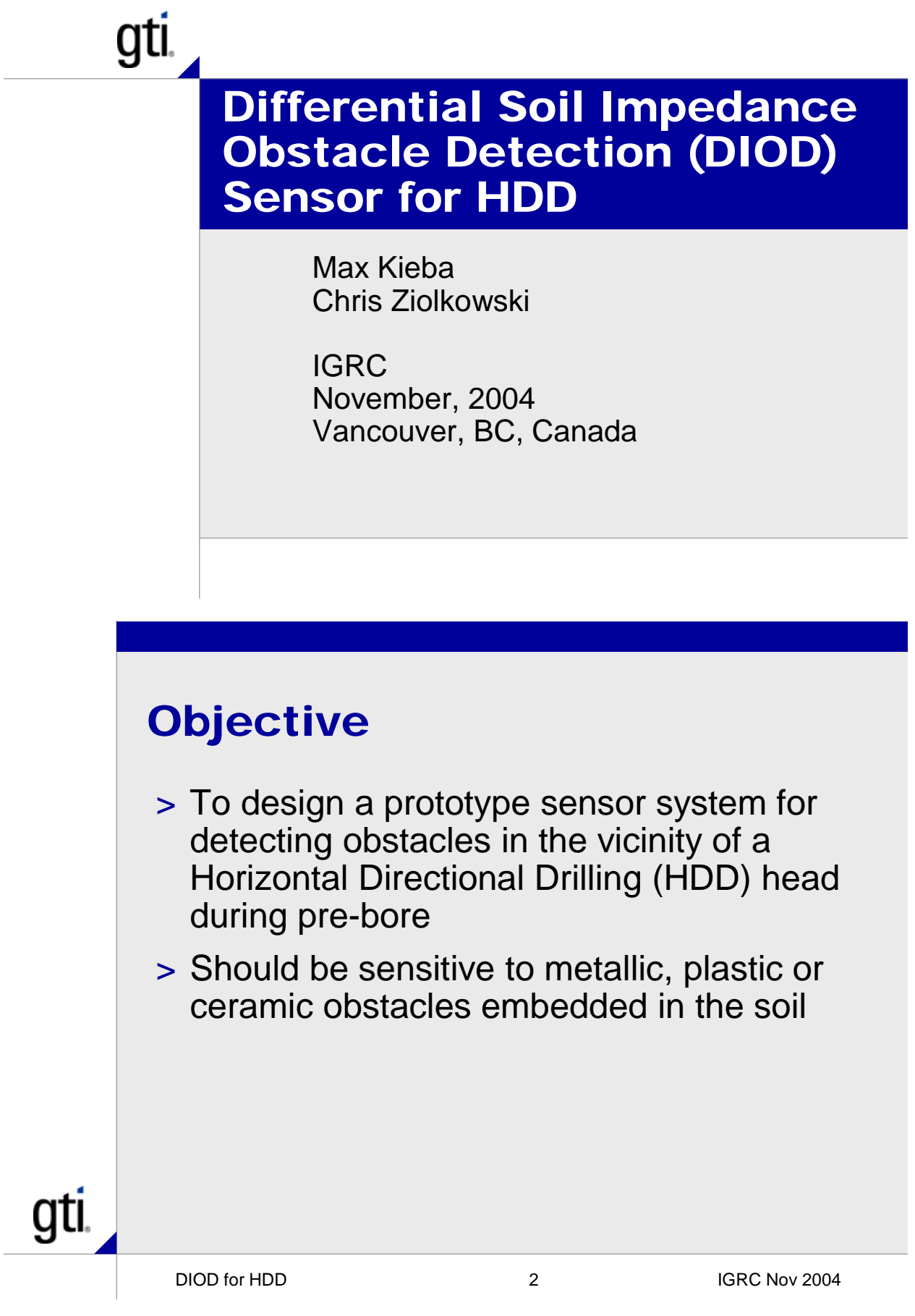




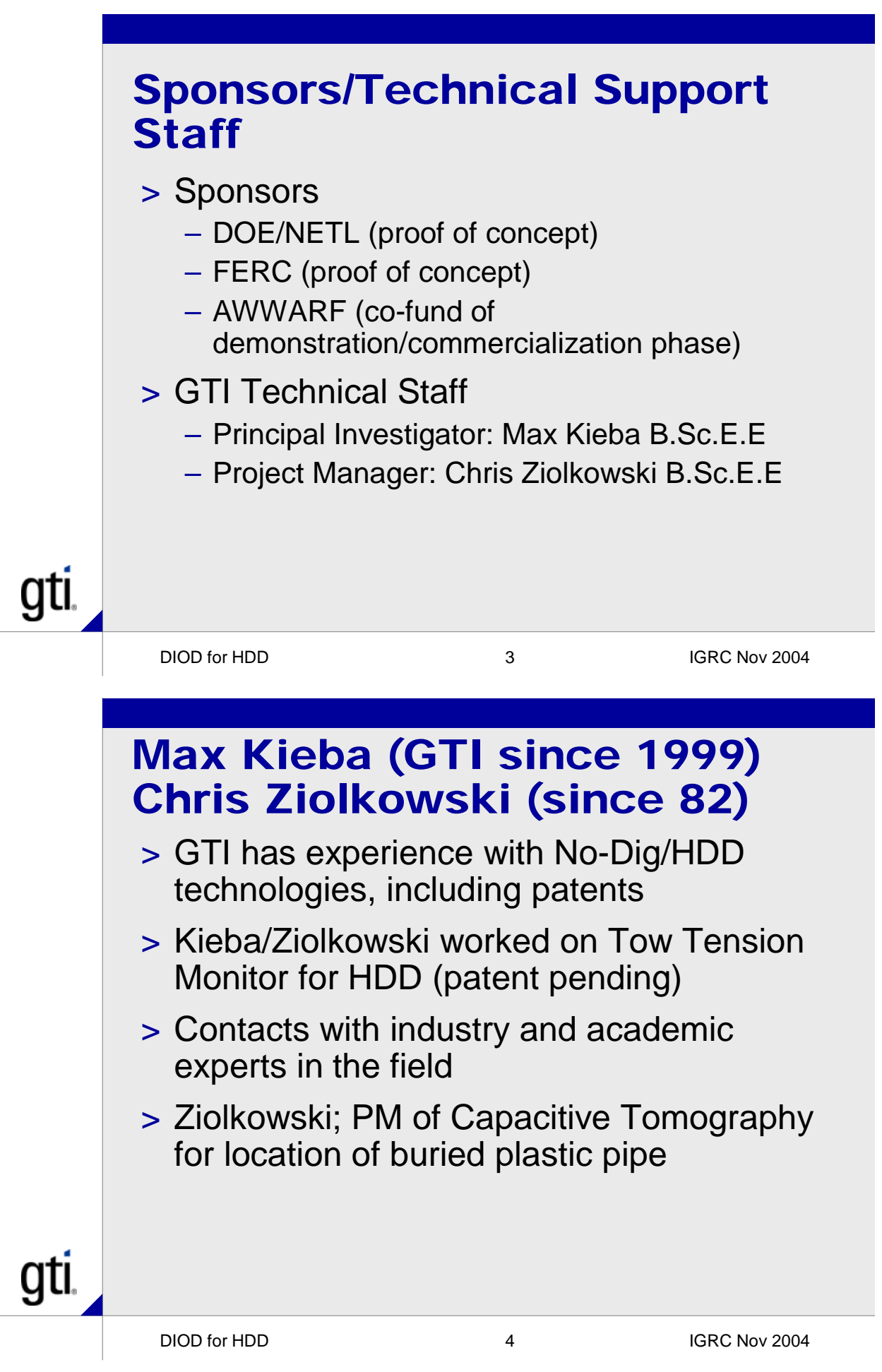




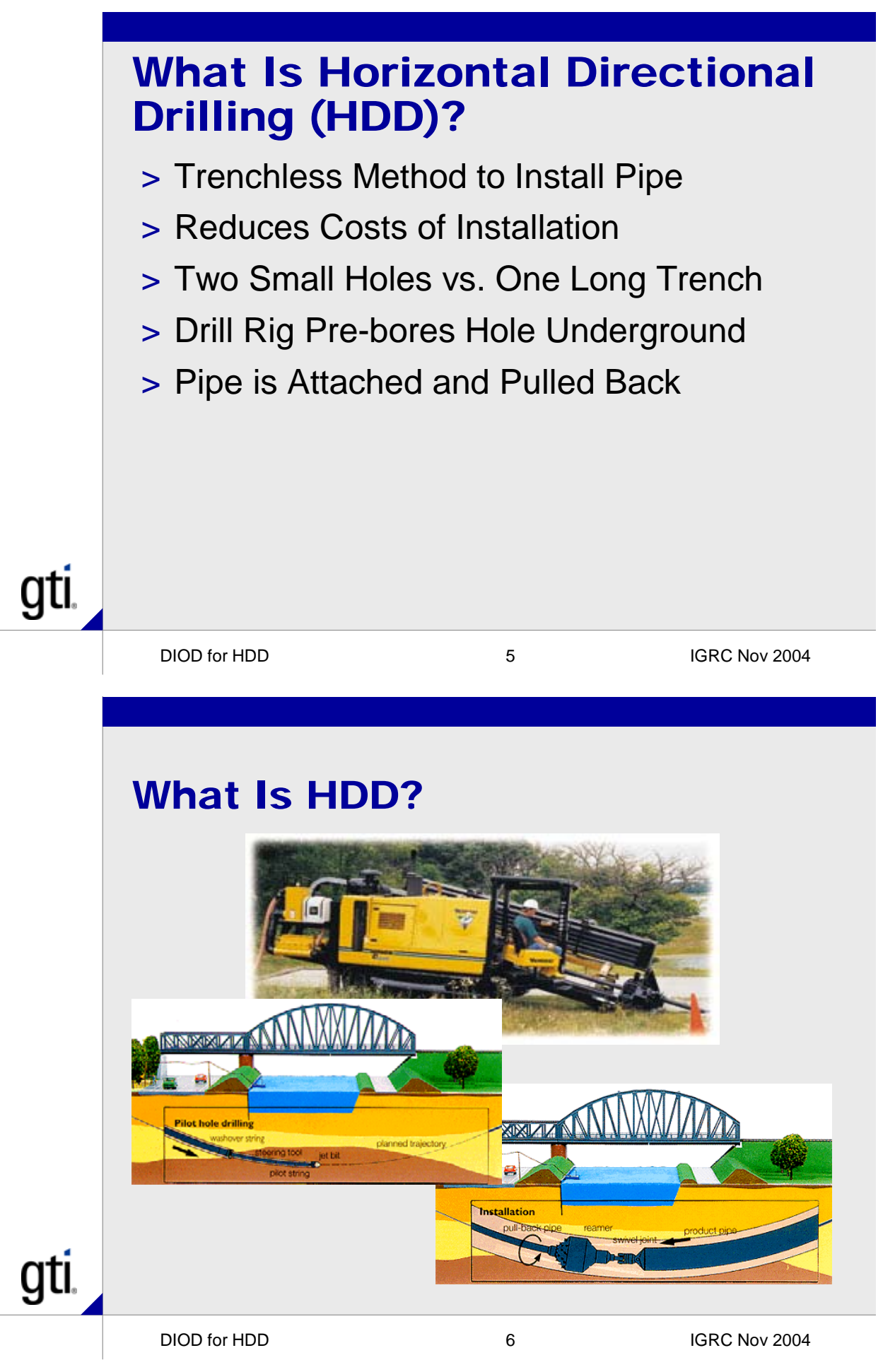




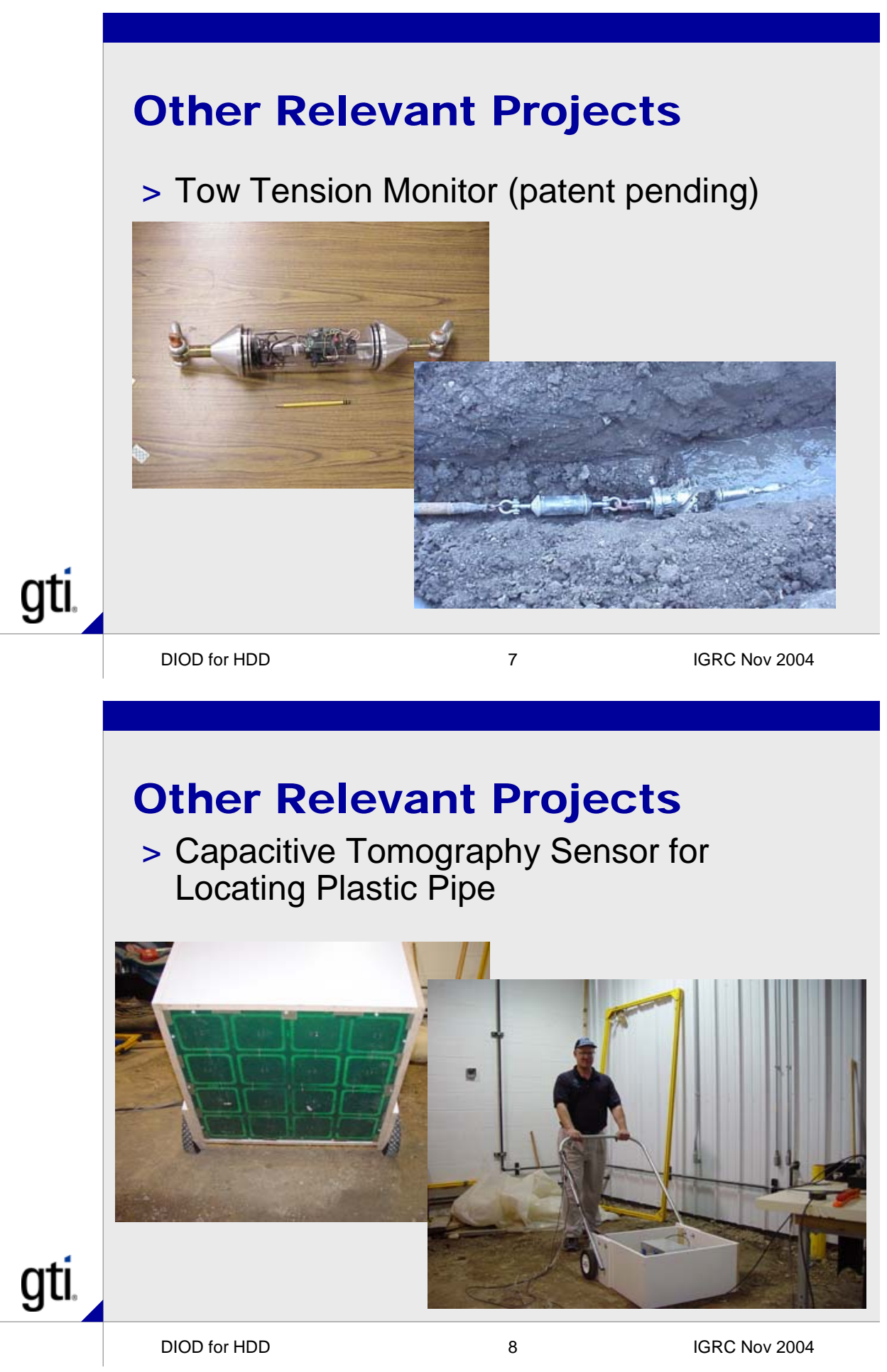




\section{Why Do We Need the DIOD?}

$>$ With reduced installation costs and increased use of HDD comes crowded utility easements

$>$ In the last few years, there have been a few extreme incidents of damage resulting from drill collisions with buried facilities

$>$ Thousands of other utility strikes on gas, electric, telecommunications, water and sewer lines occur annually

gti.

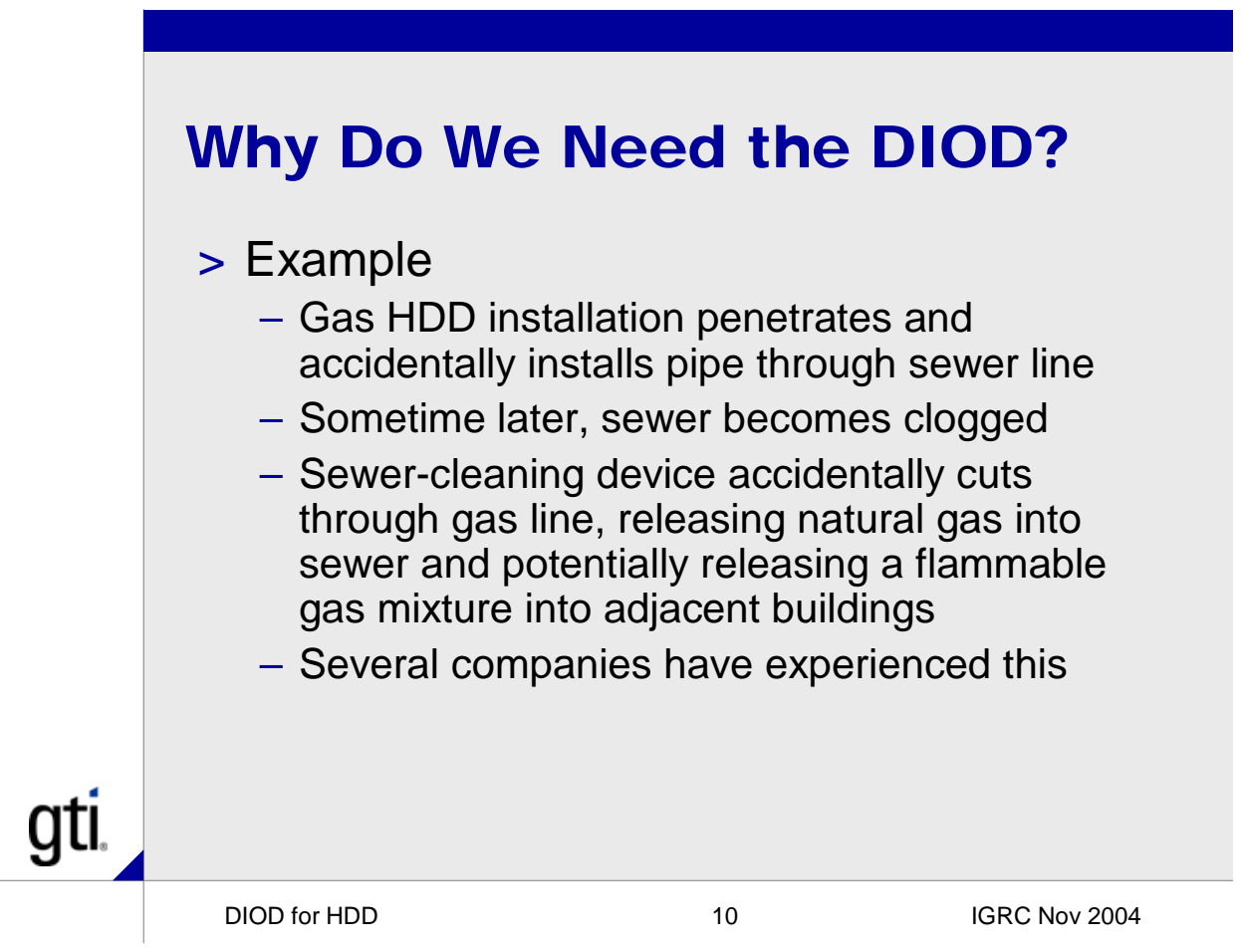




\section{Why Do We Need the DIOD?}

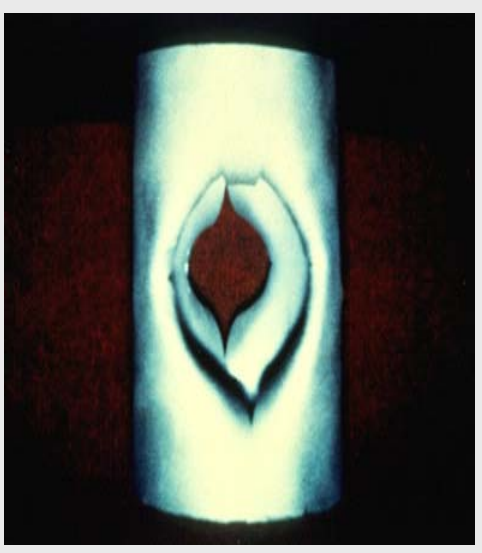

gti.

Damage to lead sewer pipe from HDD tool

\section{Initial Technical Approach}

\section{$>$ Initial Proposal Concept}
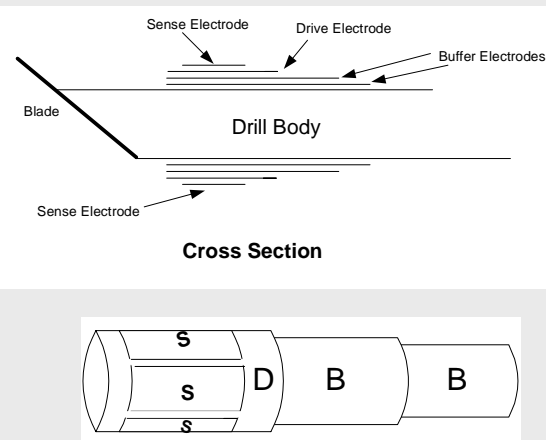

gti. 


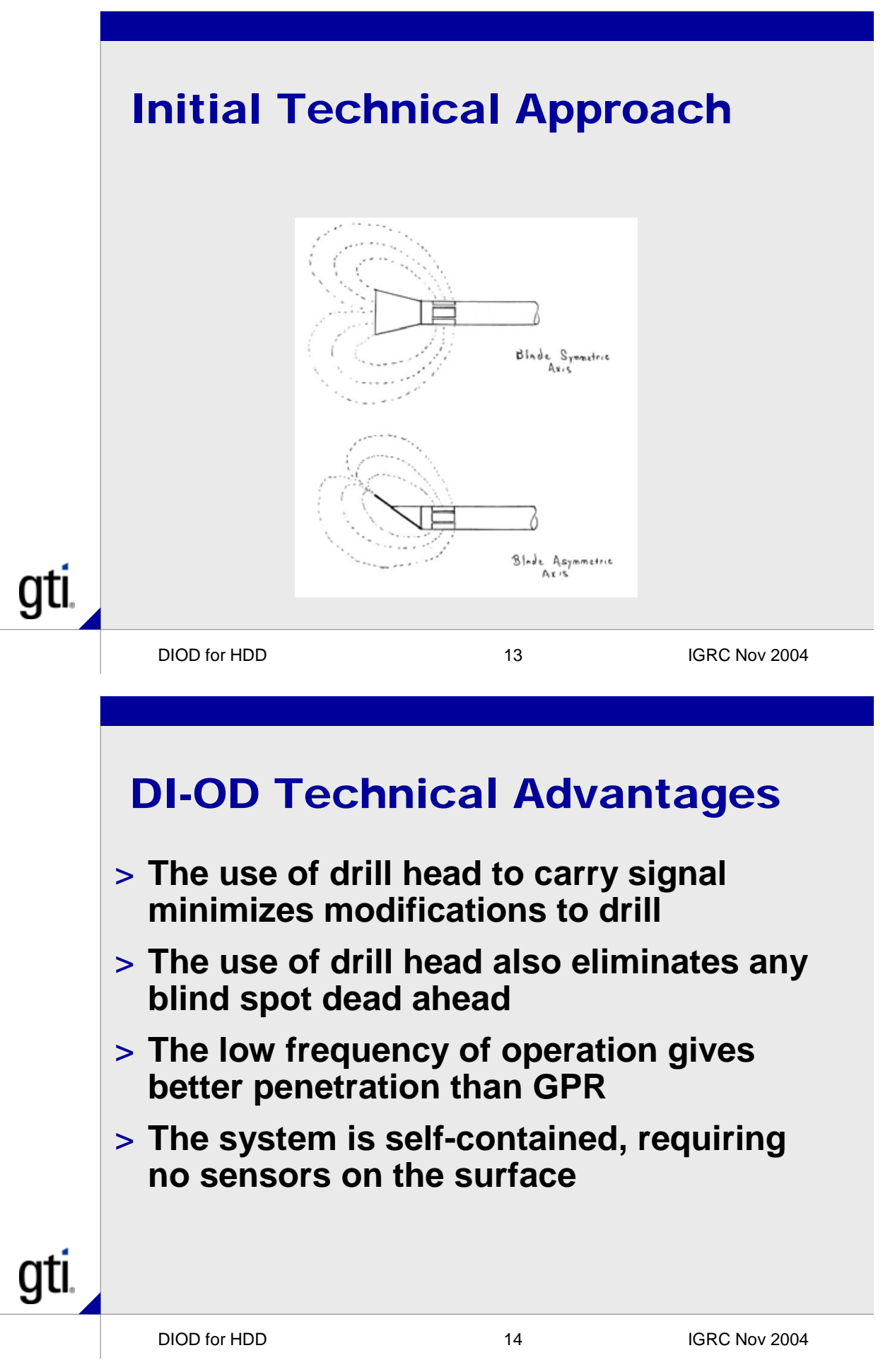




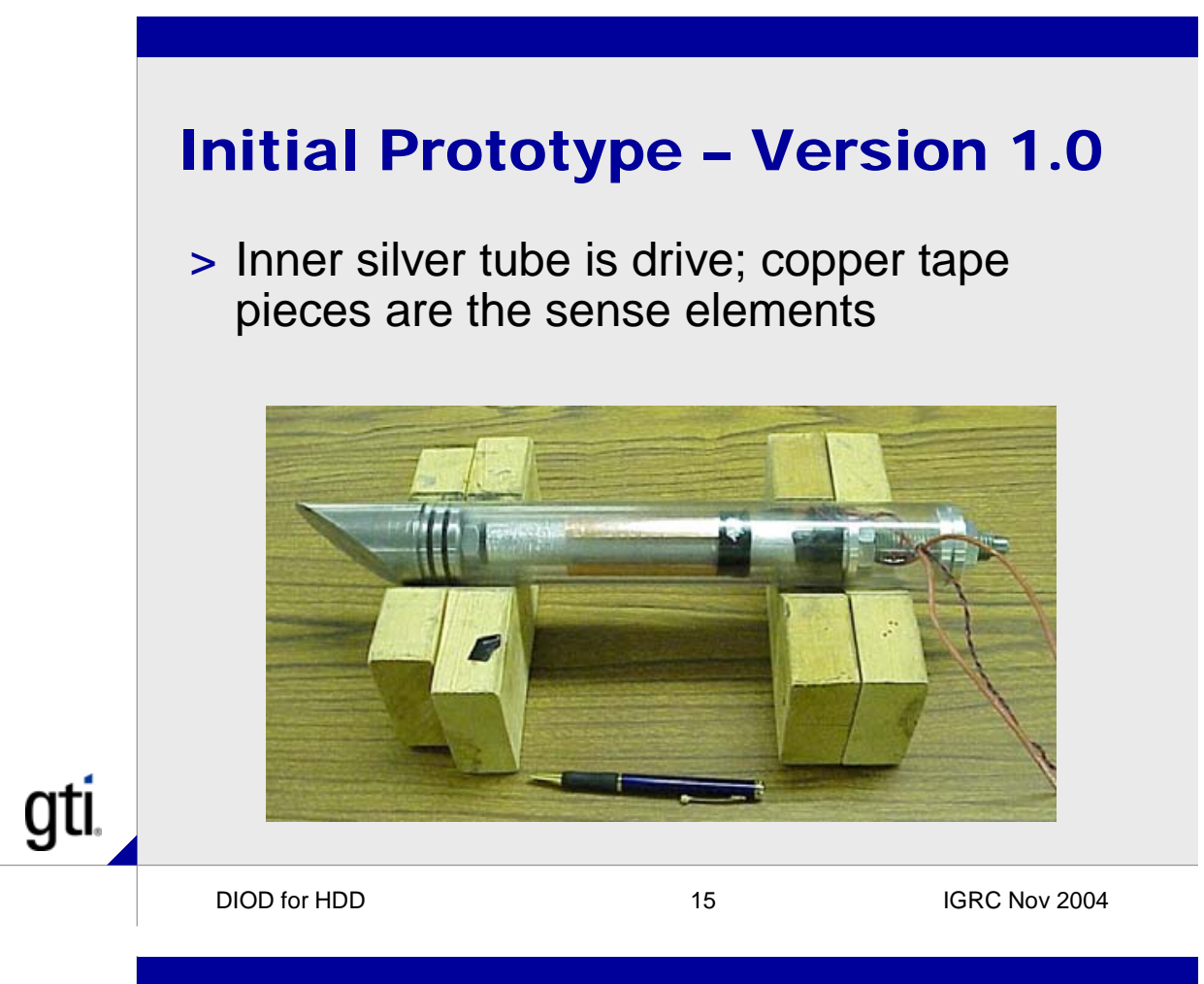

\section{Results Of Version 1.0}

$>$ Sensitivity lower than expected

$>$ Concerns with effects of adding several hundred feet of drill pipe aft of the sensor

- Current flow also likely be from drill pipe

- Wish to force the sensing current ahead of drill through the tip

gti. 


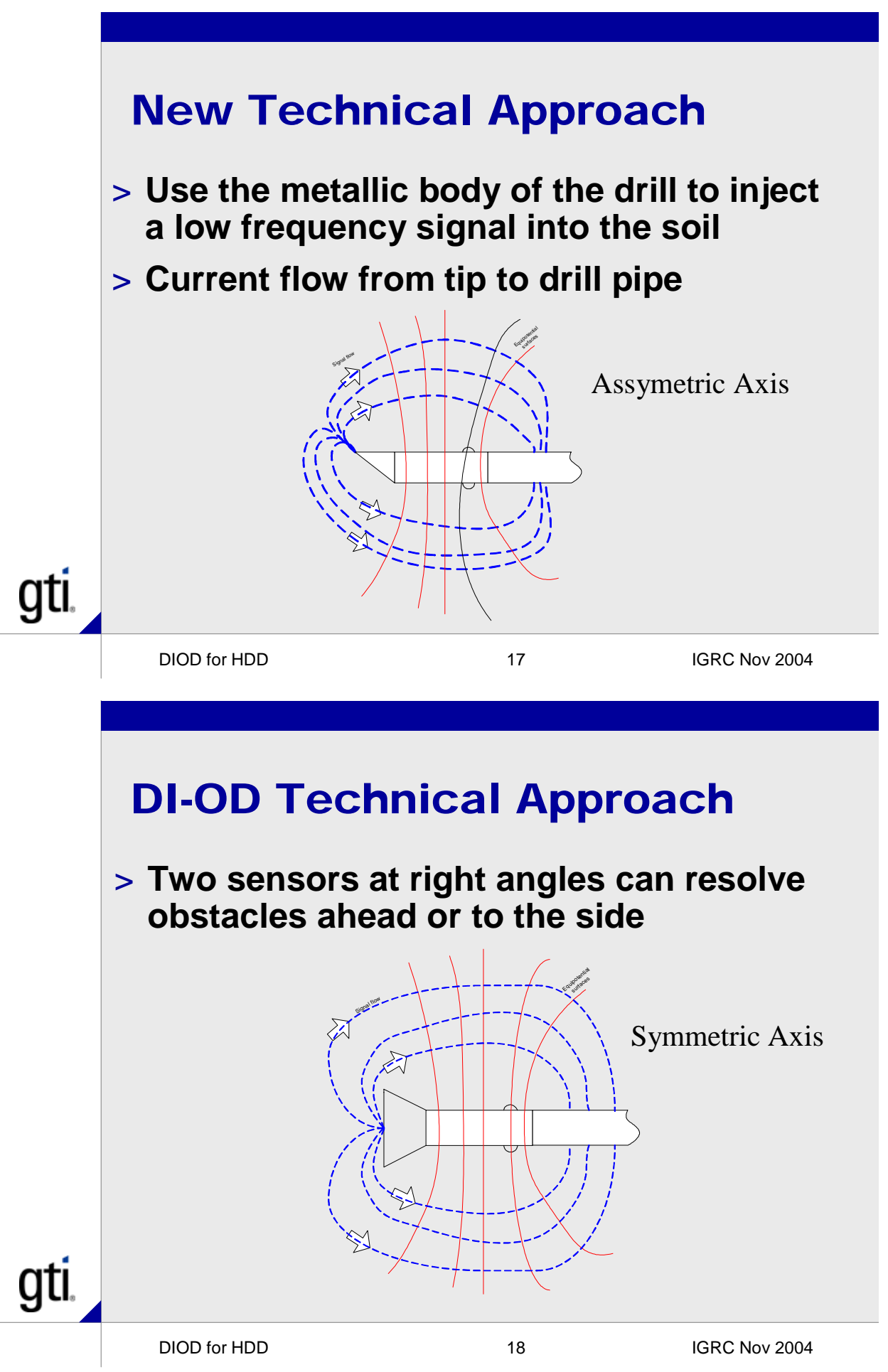




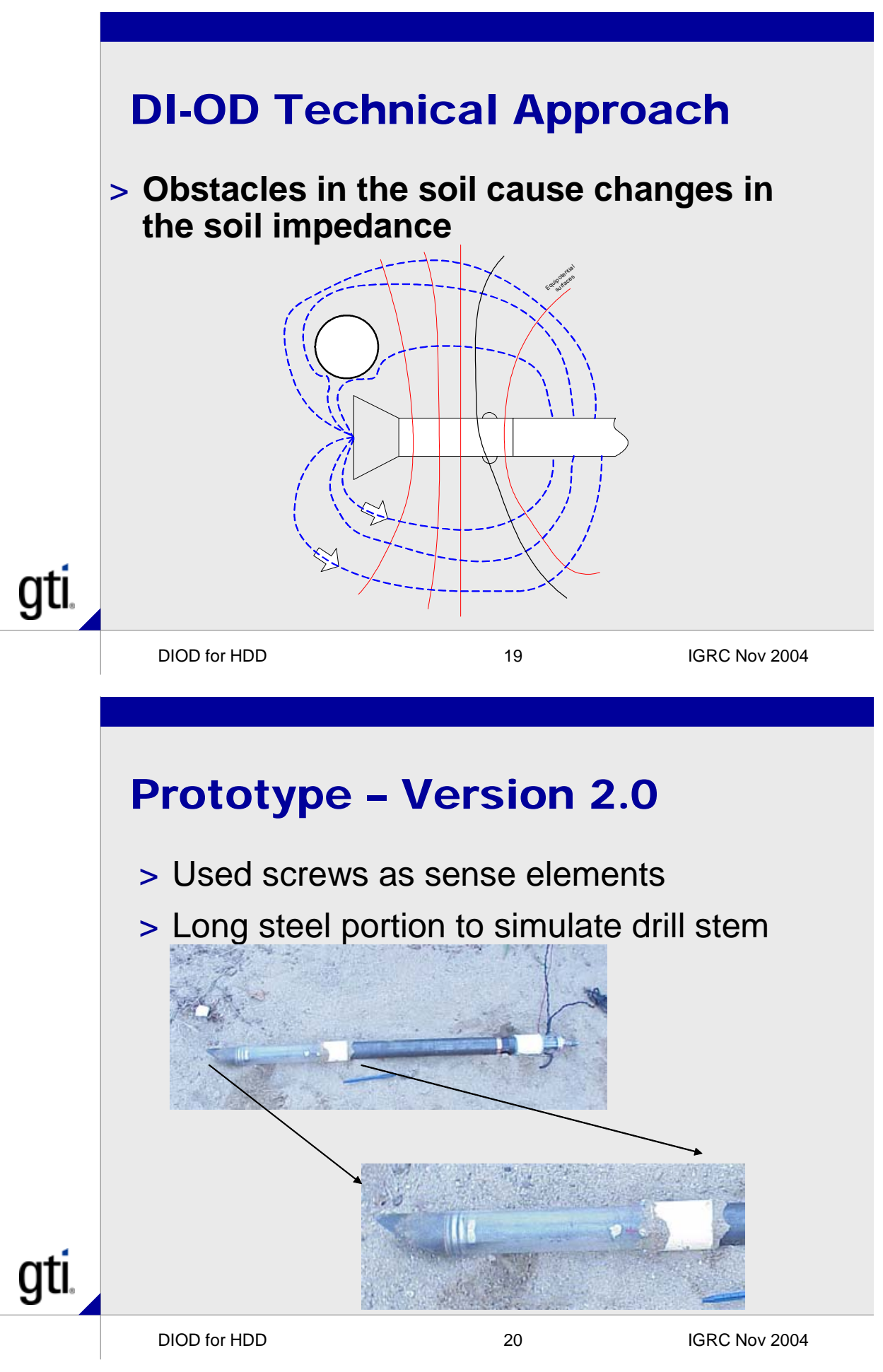




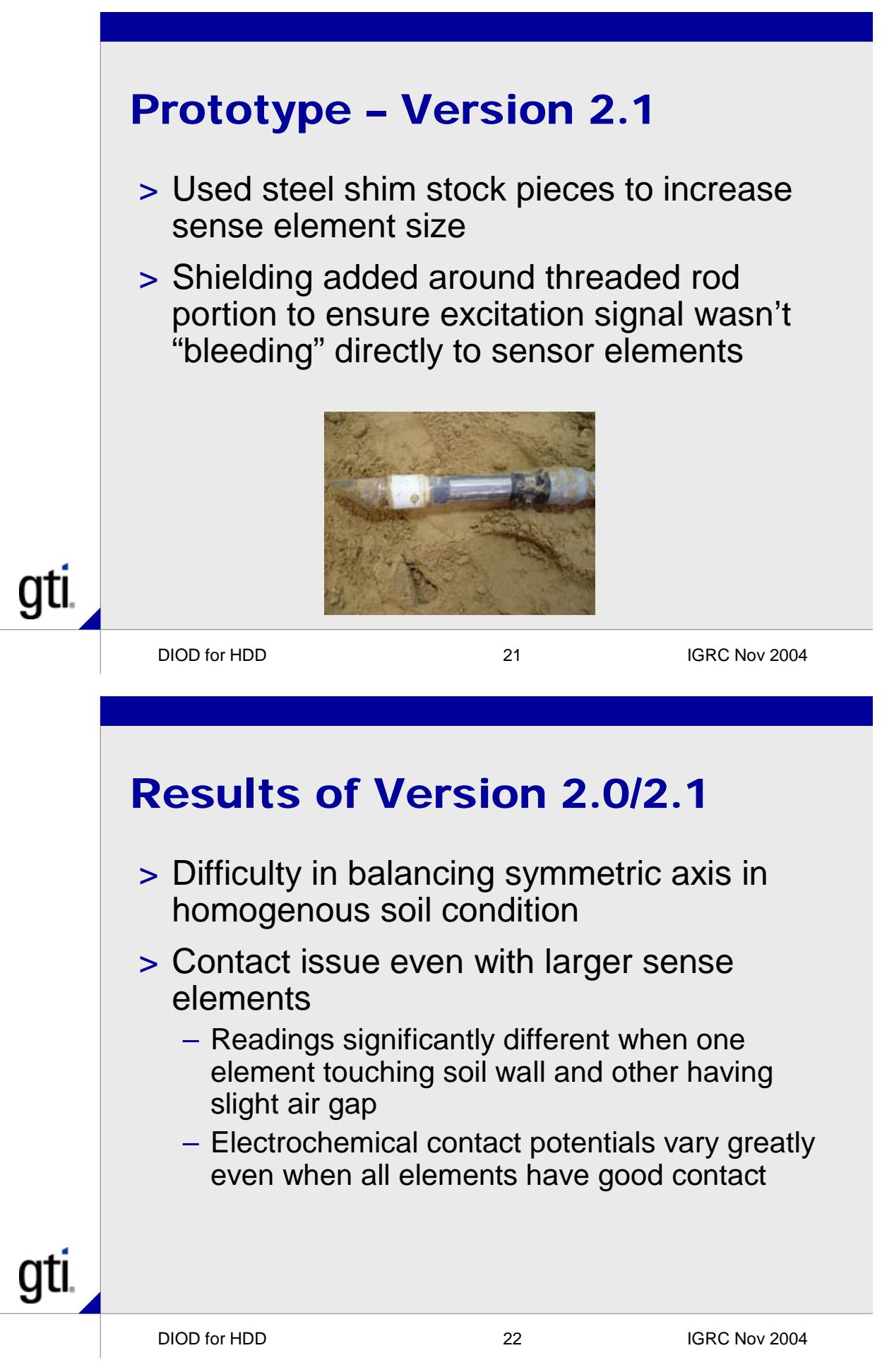




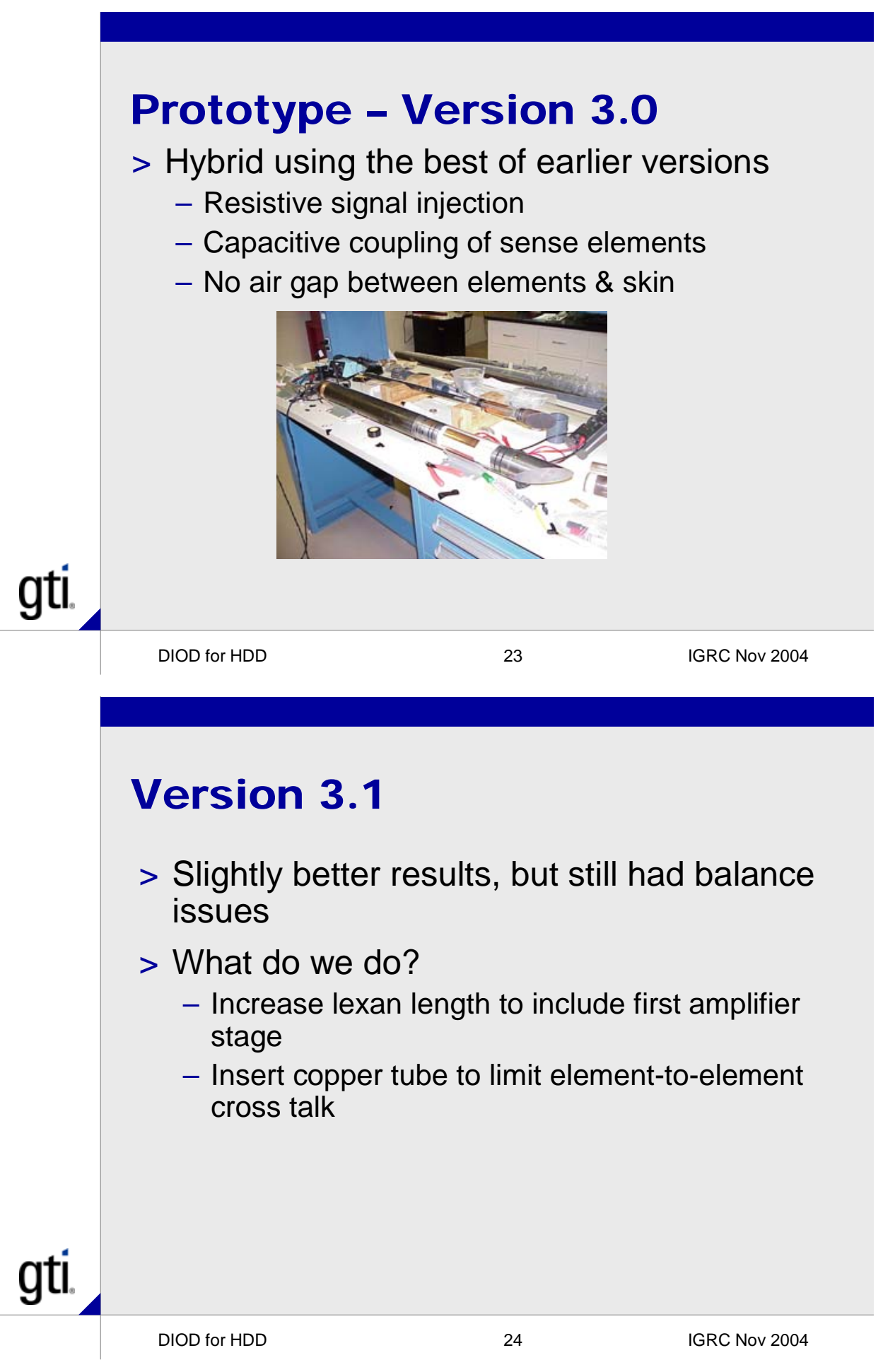




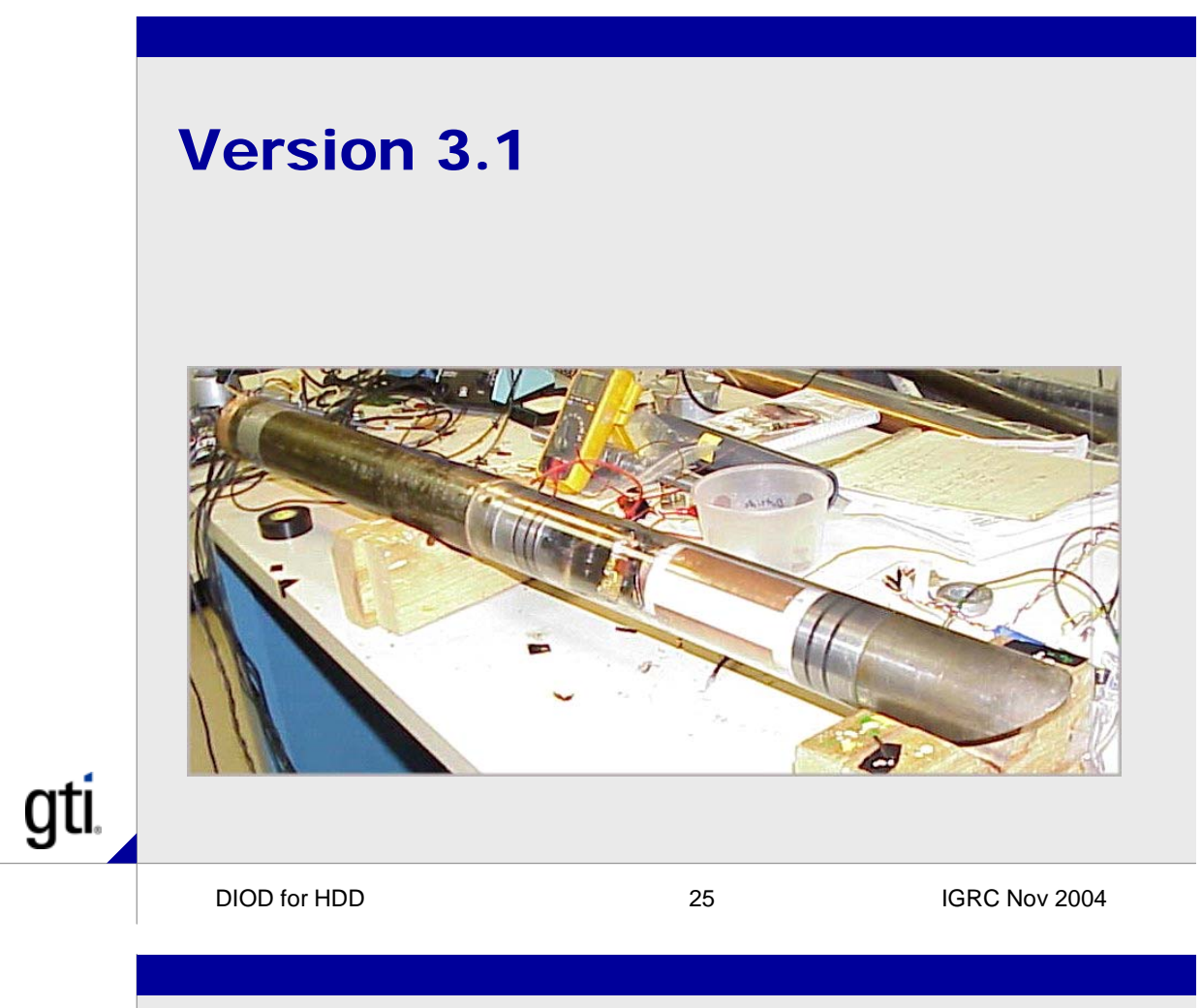

\section{Version 3.1}

gti.

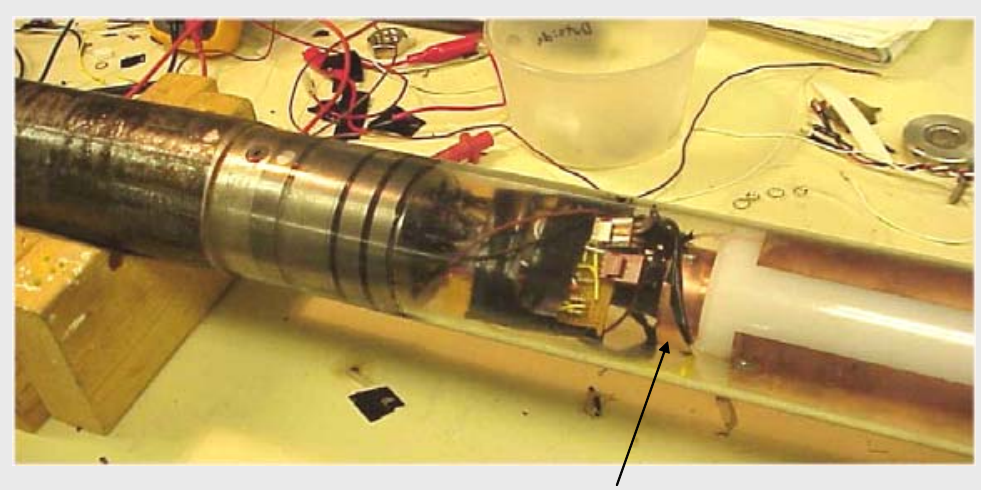

Shielding

DIOD for HDD

26

IGRC Nov 2004 


\section{Version 3.1 Results}

$>$ Able to achieve balanced condition by adjusting excitation signal phase with respect to reference signal

$>$ In bench tests, medium is air

$>$ Equal sizes of copper and plastic tubes placed near symmetric axis elements

$>$ Copper caused larger imbalance, as expected in air

gti.

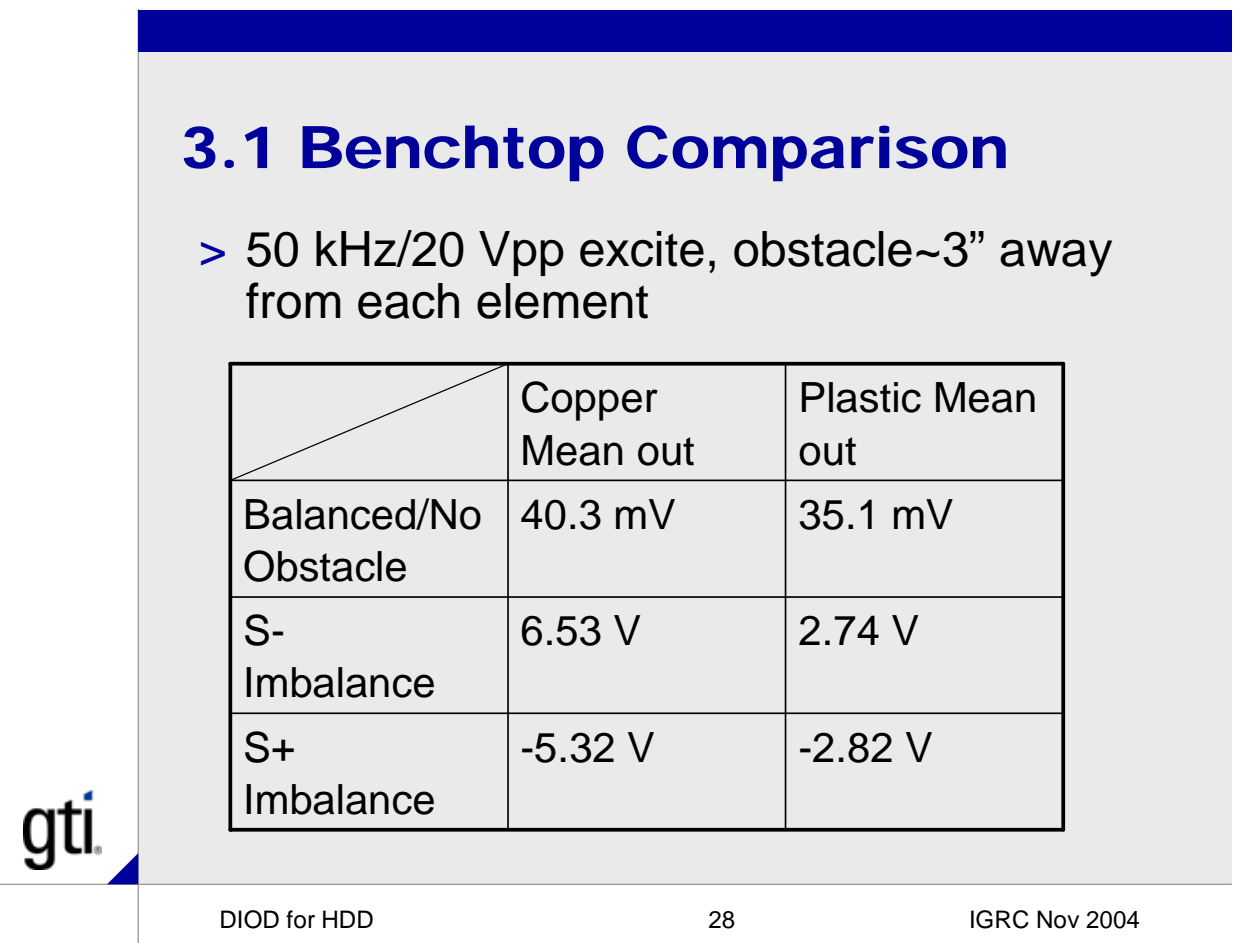




\section{Version 3.1 Tests With Copper}

$>$ Green=ref signal; blue=instrumentation amp output; pink=lock-in out; yellow=filtered output

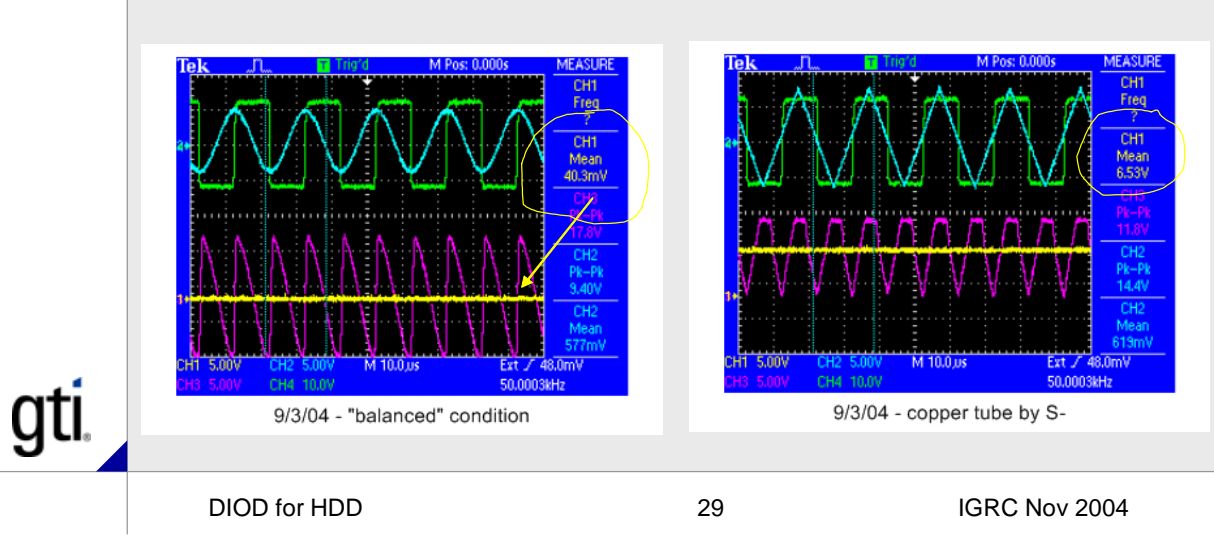

\section{Version 3.1 Copper (Cont'd)}

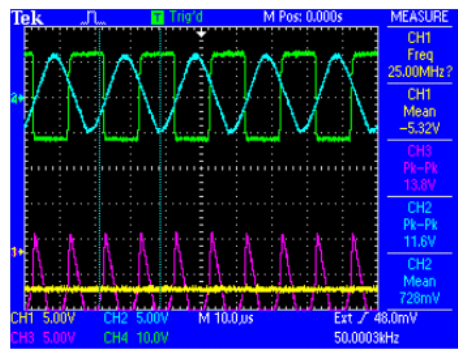

090304 - copper tube on S+

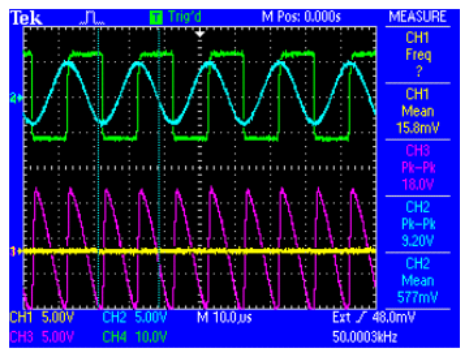

090304 - back to no obstacle

gti. 


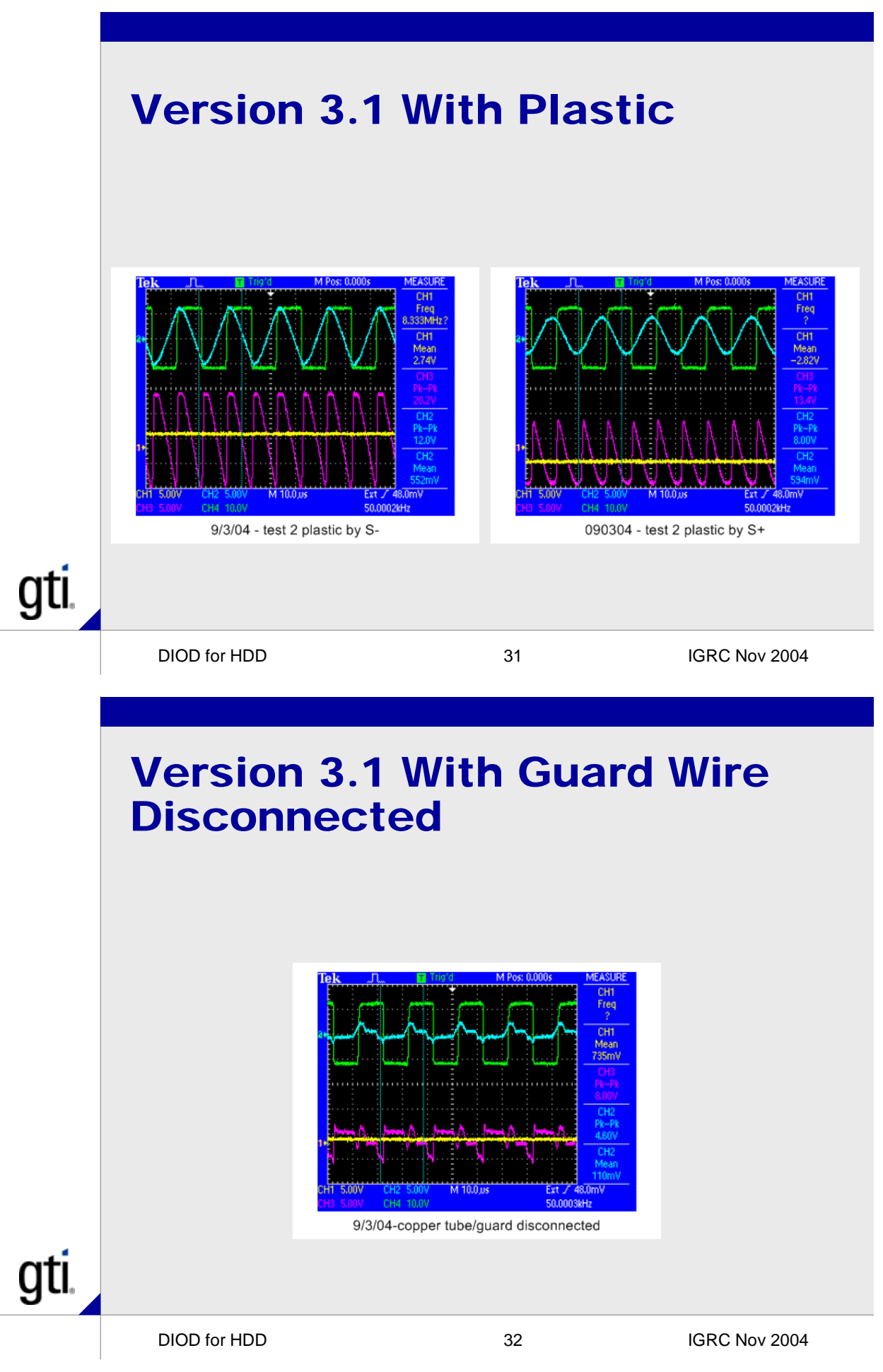




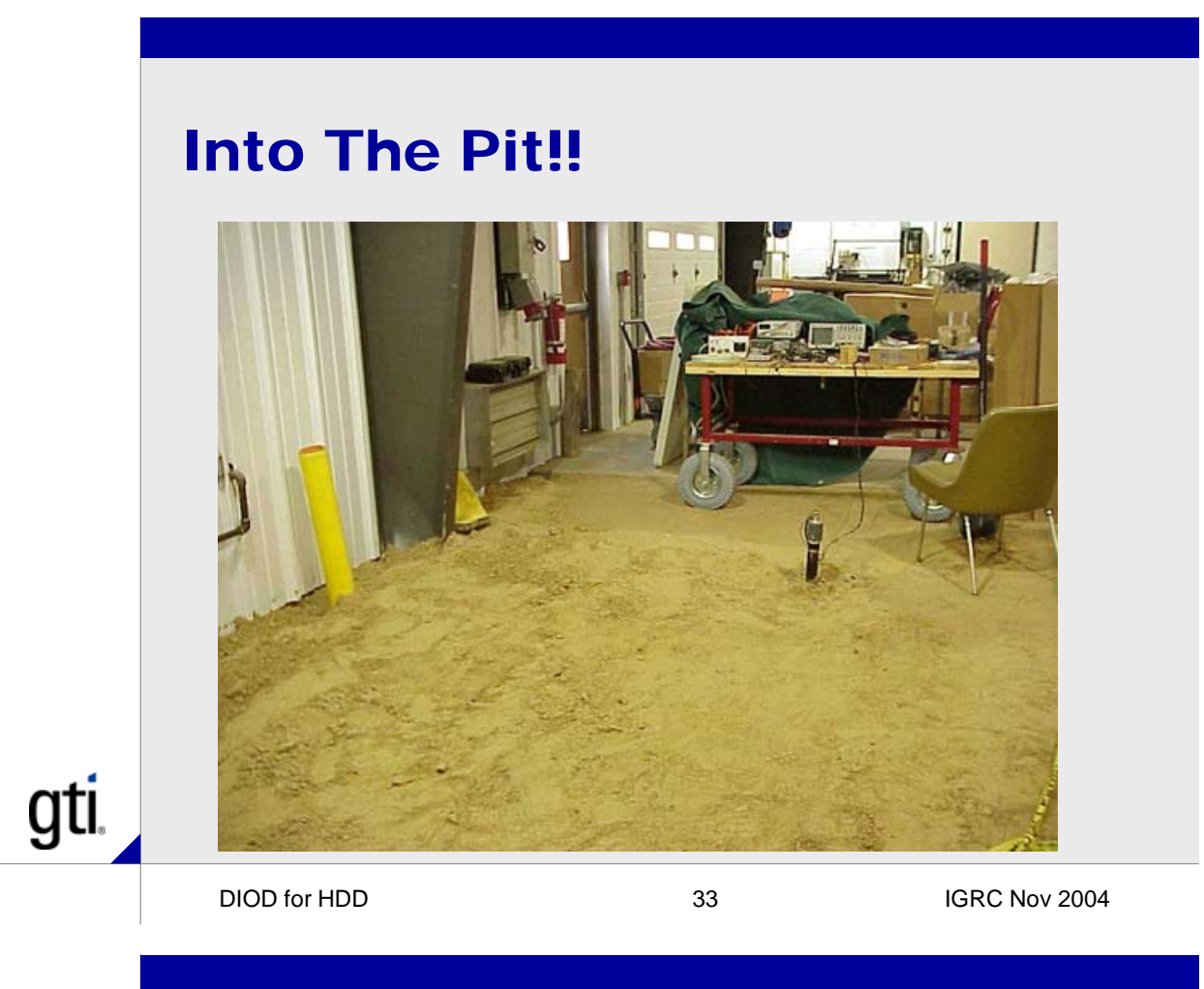

\section{Tests in Loam Soil}

$>25 \mathrm{kHz}$ excitation, 4" PE pipe $\sim 3$ ' deep and 6 " from sensor

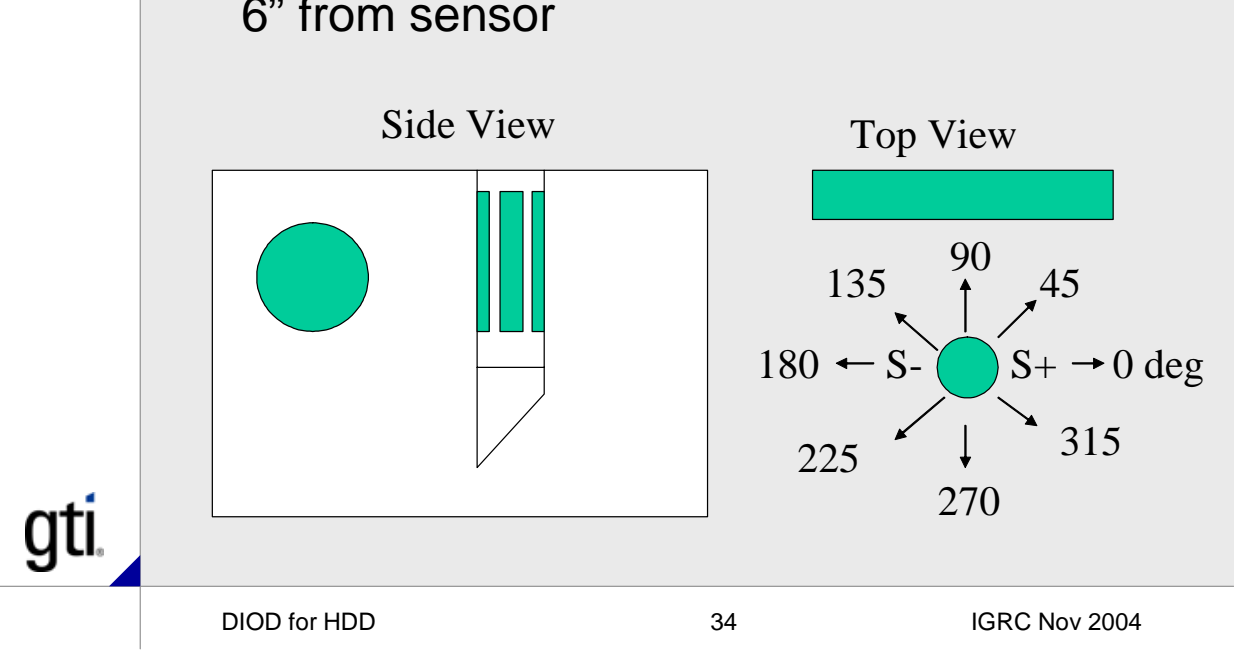




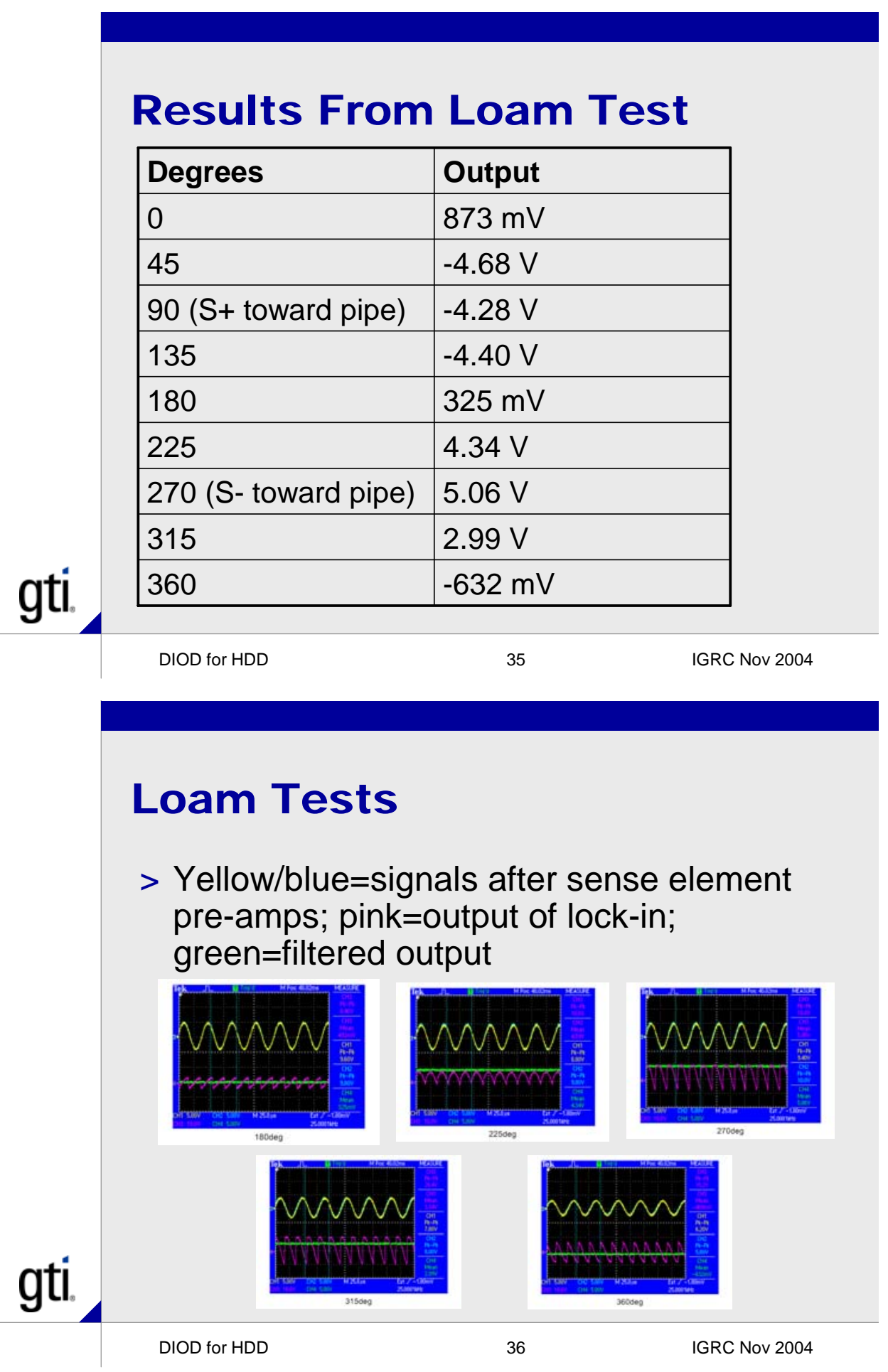




\section{So What's Wrong?}

$>$ Still having some contact/repeatability issues between tests in soil

- Believe contact issue may be a result of tip drilling out air pocket during rotation
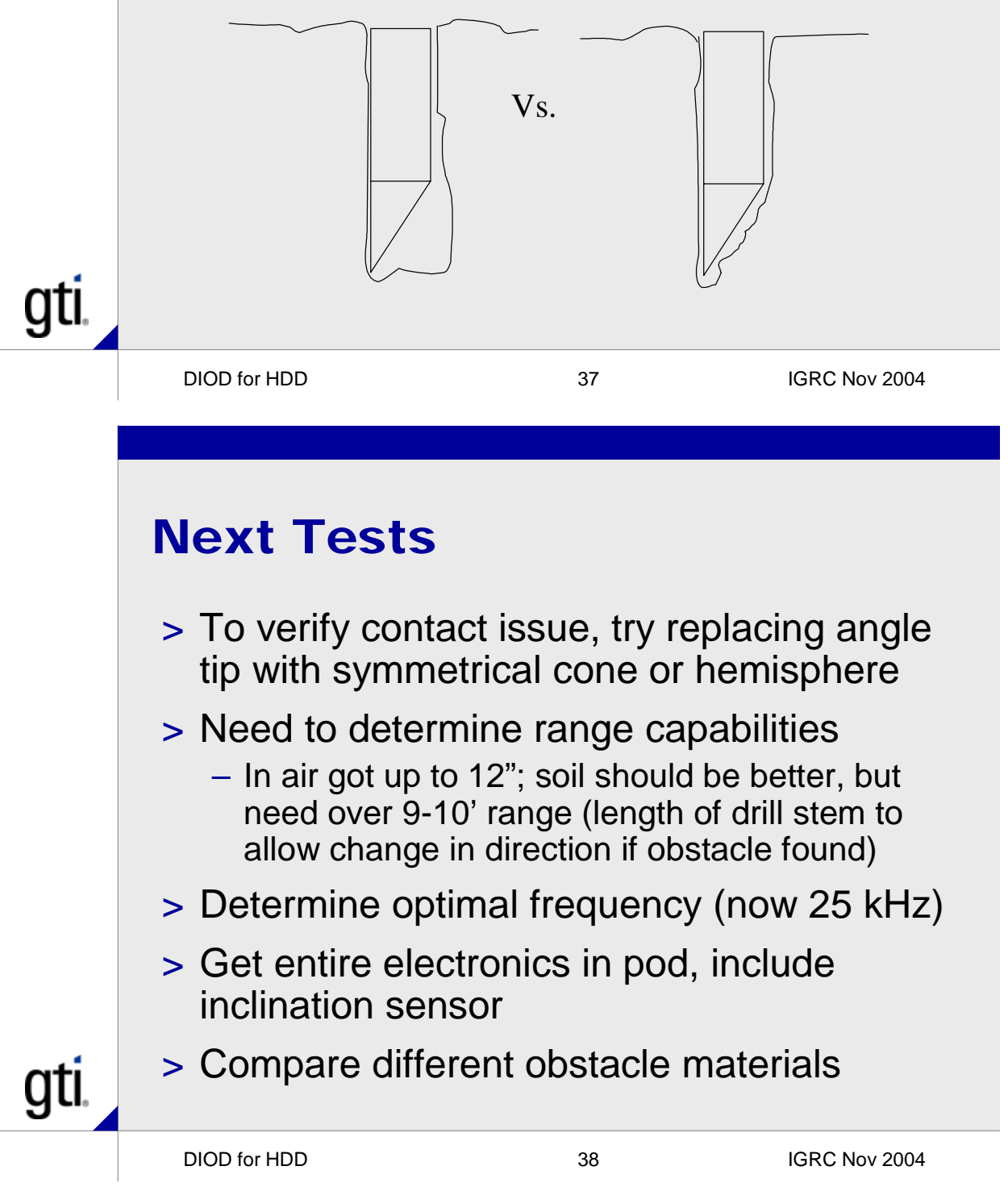


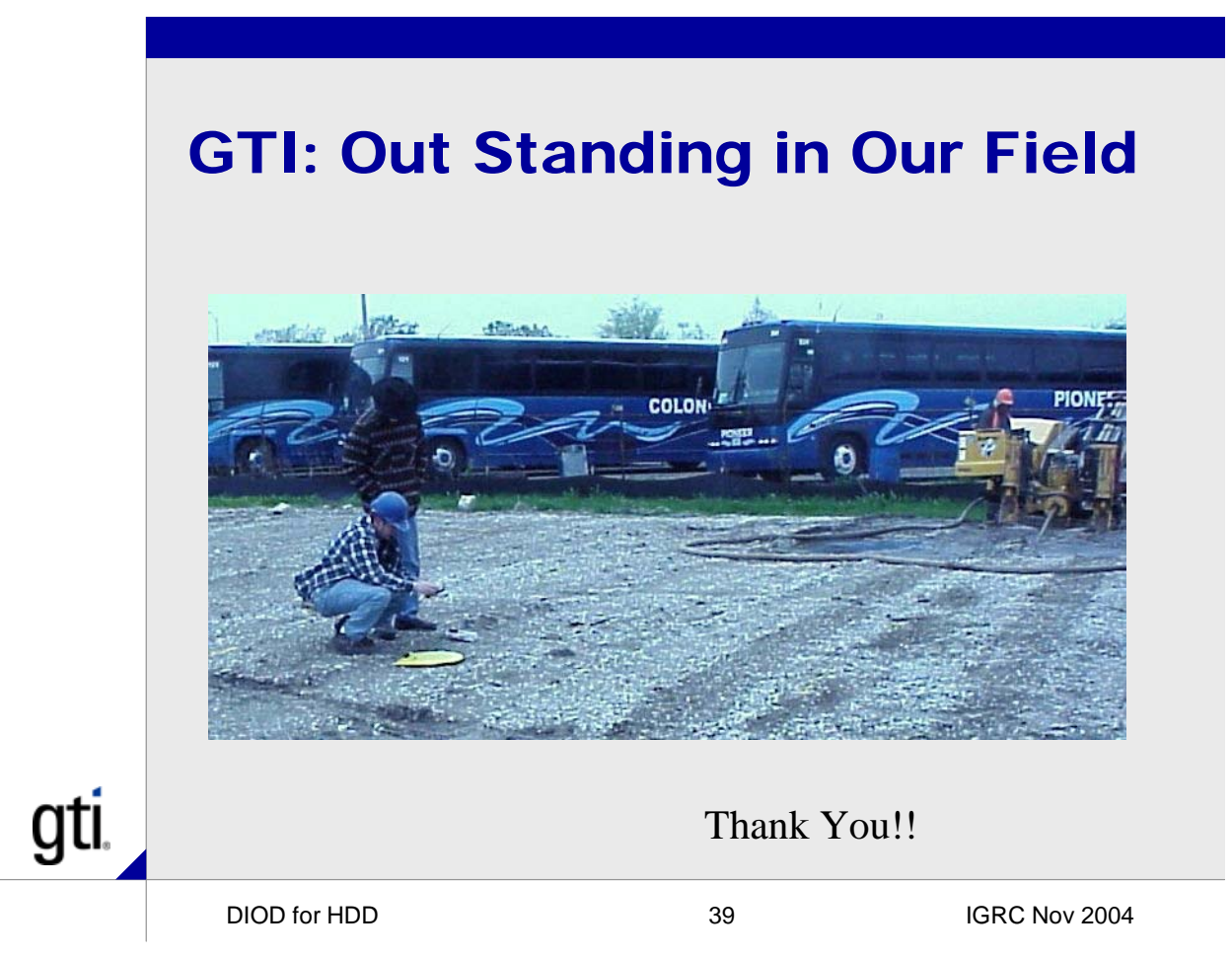

